\title{
Sources, transport and deposition of iron in the global atmosphere
}

\author{
R. Wang ${ }^{1,2,3}$, Y. Balkanski ${ }^{1,3}$, O. Boucher ${ }^{4}$, L. Bopp ${ }^{1}$, A. Chappell ${ }^{5}$, P. Ciais ${ }^{1,3}$, D. Hauglustaine ${ }^{1}$, J. Peñuelas ${ }^{6,7}$, and \\ S. Tao $^{2,3}$ \\ ${ }^{1}$ Laboratoire des Sciences du Climat et de l'Environnement, CEA CNRS UVSQ, Gif-sur-Yvette, France \\ ${ }^{2}$ Laboratory for Earth Surface Processes, College of Urban and Environmental Sciences, Peking University, Beijing, China \\ ${ }^{3}$ Sino-French Institute for Earth System Science, College of Urban and Environmental Sciences, Peking University, \\ Beijing, China \\ ${ }^{4}$ Laboratoire de Météorologie Dynamique, IPSL/CNRS, Université Pierre et Marie Curie, Paris, France \\ ${ }^{5}$ CSIRO Land \& Water National Research Flagship, G.P.O. Box 1666, Canberra, ACT 2601, Australia \\ ${ }^{6}$ CSIC, Global Ecology Unit CREAF-CEAB-UAB, Cerdanyola del Vallès, 08193 Catalonia, Spain \\ ${ }^{7}$ CREAF, Cerdanyola del Vallès, 08193 Catalonia, Spain
}

Correspondence to: R. Wang (rong.wang @1sce.ipsl.fr)

Received: 30 December 2014 - Published in Atmos. Chem. Phys. Discuss.: 12 March 2015

Revised: 11 May 2015 - Accepted: 13 May 2015 - Published: 8 June 2015

\begin{abstract}
Atmospheric deposition of iron (Fe) plays an important role in controlling oceanic primary productivity. However, the sources of $\mathrm{Fe}$ in the atmosphere are not well understood. In particular, the combustion sources of Fe and the subsequent deposition to the oceans have been accounted for in only few ocean biogeochemical models of the carbon cycle. Here we used a mass-balance method to estimate the emissions of $\mathrm{Fe}$ from the combustion of fossil fuels and biomass by accounting for the $\mathrm{Fe}$ contents in fuel and the partitioning of Fe during combustion. The emissions of $\mathrm{Fe}$ attached to aerosols from combustion sources were estimated by particle size, and their uncertainties were quantified by a Monte Carlo simulation. The emissions of Fe from mineral sources were estimated using the latest soil mineralogical database to date. As a result, the total $\mathrm{Fe}$ emissions from combustion averaged for 1960-2007 were estimated to be $5.3 \mathrm{Tg} \mathrm{yr}^{-1}$ (90\% confidence of 2.3 to 12.1). Of these emissions, 1,27 and $72 \%$ were emitted in particles $<1 \mu \mathrm{m}$ $\left(\mathrm{PM}_{1}\right), 1-10 \mu \mathrm{m}\left(\mathrm{PM}_{1-10}\right)$, and $>10 \mu \mathrm{m}\left(\mathrm{PM}_{>} 10\right)$, respectively, compared to a total Fe emission from mineral dust of $41.0 \mathrm{Tg} \mathrm{yr}^{-1}$ in a log-normal distribution with a mass median diameter of $2.5 \mu \mathrm{m}$ and a geometric standard deviation of 2. For combustion sources, different temporal trends were found in fine and medium-to-coarse particles, with a notable increase in $\mathrm{Fe}$ emissions in $\mathrm{PM}_{1}$ since 2000 due to an increase in $\mathrm{Fe}$ emission from motor vehicles (from 0.008 to $0.0103 \mathrm{Tg} \mathrm{yr}^{-1}$ in 2000 and 2007, respectively). These emis-
\end{abstract}

sions have been introduced in a global 3-D transport model run at a spatial resolution of $0.94^{\circ}$ latitude by $1.28^{\circ}$ longitude to evaluate our estimation of $\mathrm{Fe}$ emissions. The modelled $\mathrm{Fe}$ concentrations as monthly means were compared with the monthly (57 sites) or daily (768 sites) measured concentrations at a total of 825 sampling stations. The deviation between modelled and observed $\mathrm{Fe}$ concentrations attached to aerosols at the surface was within a factor of 2 at most sampling stations, and the deviation was within a factor of 1.5 at sampling stations dominated by combustion sources. We analysed the relative contribution of combustion sources to total $\mathrm{Fe}$ concentrations over different regions of the world. The new mineralogical database led to a modest improvement in the simulation relative to station data even in dust-dominated regions, but could provide useful information on the chemical forms of $\mathrm{Fe}$ in dust for coupling with ocean biota models. We estimated a total Fe deposition sink of $8.4 \mathrm{Tg} \mathrm{yr}^{-1}$ over global oceans, $7 \%$ of which originated from the combustion sources. Our central estimates of $\mathrm{Fe}$ emissions from fossil fuel combustion (mainly from coal) are generally higher than those in previous studies, although they are within the uncertainty range of our estimates. In particular, the higher than previously estimated $\mathrm{Fe}$ emission from coal combustion implies a larger atmospheric anthropogenic input of soluble Fe to the northern Atlantic and northern Pacific Oceans, which is expected to enhance the biological carbon pump in those regions. 


\section{Introduction}

Sea-water dissolved iron $(\mathrm{Fe})$ concentration is a primary factor that limits or co-limits the growth of phytoplankton in large regions of the global oceans (Martin et al., 1991; Moore et al., 2013). As such, Fe availability influences the transfer and sequestration of carbon into the deep ocean (Boyd et al., 2000; Moore et al., 2004). Both ice-core and marinesediment records indicate high rates of aeolian dust and hence Fe supply to the oceans at the Last Glacial Maximum, implying a potential link between Fe availability, marine productivity, atmospheric $\mathrm{CO}_{2}$ and climate through Fe fertilization (Martin, 1990; Ridgwell and Watson, 2002). Over the Industrial Era, the increase of $\mathrm{Fe}$ deposition in dust was estimated to be responsible for a decrease of atmospheric $\mathrm{CO}_{2}$ by 4 ppm (Mahowald et al., 2011), with a large uncertainty.

Atmospheric deposition provides an important source of $\mathrm{Fe}$ to the marine biota (Martin, 1990; Duce and Tindale, 1991; Johnson et al., 1997; Fung et al., 2000; Gao et al., 2001; Conway and John, 2014). Early studies of the effects of Fe fertilization, however, mostly focused on aeolian dust sources (Hand et al., 2004; Luo et al., 2003; Gregg et al., 2003; Moore et al., 2004; Mahowald et al., 2005; Fan et al., 2006). Observed concentrations of soluble Fe were not properly captured by the models simulating the atmospheric transport, chemical processing and deposition of $\mathrm{Fe}$ in aerosols (Hand et al., 2004; Luo et al., 2005; Fan et al., 2006), thus suggesting the existence of other sources. Guieu et al. (2005) proposed that the burning of biomass could be an additional source of soluble Fe in the Ligurian Sea. Chuang et al. (2005) reported that soluble Fe observed at an atmospheric deposition measurement station in Korea was not dominated by mineral sources, even during dust storms. Sedwick et al. (2007) hypothesized that the anthropogenic emissions of Fe from combustion could play a significant role in the atmospheric input of bioavailable Fe to the surface of the Atlantic Ocean. However, few global models have accounted for the impact of $\mathrm{Fe}$ from combustion on the open-ocean biogeochemistry (Krishnamurthy et al., 2009; Okin et al., 2011), due to large uncertainties for the sources and chemical forms of $\mathrm{Fe}$ from combustion.

The first estimate of $\mathrm{Fe}$ emissions from fossil fuels and biomass burning reported a total $\mathrm{Fe}$ emission of $1.7 \mathrm{Tg} \mathrm{yr}^{-1}$ (Luo et al., 2008). Ito and Feng (2010) subsequently obtained a lower estimate of $1.2 \mathrm{Tg} \mathrm{yr}^{-1}$. By applying a high emission factor of Fe from ships and accounting for a large Fe solubility from oil fly ash, Ito (2013) later derived the same total Fe emission of $1.2 \mathrm{Tg} \mathrm{yr}^{-1}$, but with a significant contribution by shipping to soluble Fe deposition over the northern Pacific Ocean and the East China Sea. These authors suggested that more work was required to reduce the uncertainty in Fe emissions, particularly from the combustion of petroleum and biomass.

The mineral composition of dust is a key factor in the chemical forms of $\mathrm{Fe}$, and it determines the solubility and thus the bioavailability of Fe. Nickovic et al. (2012) developed a global data set to represent the mineral composition of soil in arid and semi-arid areas. This mineralogical data set improved the agreement between simulated and measured concentrations of soluble $\mathrm{Fe}$ (Nickovic et al., 2013; Ito and $\mathrm{Xu}, 2014)$. More recently, Journet et al. (2014) developed a new data set of soil mineralogy (including soil Fe content) covering most dust source regions of the world at a resolution of $0.5^{\circ} \times 0.5^{\circ}$, with the aim to improve the modelling of the chemical forms of $\mathrm{Fe}$ in dust.

In this study, we estimated the emissions of Fe from combustion sources for 222 countries/territories over the 1960 to 2007 period using a new method based on Fe content of fuel and $\mathrm{Fe}$ budget during combustion. We re-estimated $\mathrm{Fe}$ emissions from mineral sources based on the latest mineralogical database. Our estimates of $\mathrm{Fe}$ sources were evaluated by an atmospheric transport model at a fine resolution. The impact of the estimated combustion-related and mineral emissions of Fe on the model-data misfits at 825 stations measuring $\mathrm{Fe}$ concentration in surface aerosol and 30 stations measuring $\mathrm{Fe}$ deposition was investigated for different regions and stations.

\section{Data and methodology}

\subsection{Emissions of Fe from combustion sources}

A global emission inventory of $\mathrm{Fe}$ from combustion was developed, covering 222 countries/territories and the 1960 to 2007 period. The sources of $\mathrm{Fe}$ emission included the combustion of coal, petroleum, biofuel and biomass (55 combustion fuel types, defined in Wang et al., 2013). In contrast to previous studies (Luo et al., 2008; Ito, 2013), the emission of Fe was calculated based on the Fe content in each type of fuel, the partitioning of Fe between residue ash, cyclone ash and fly ash, the size distribution of Fe-contained particles, and the efficiency of removal by different types of control device. A similar method has been recently applied to estimate the emissions of phosphorus from combustion sources (Wang et al., 2015). Only the fly ash is emitted to the atmosphere but other types of ashes are not. For a specific combustion fuel type, the emission $(E)$ can be calculated as

$E=a \cdot b \cdot c \cdot(1-f) \cdot \sum_{x=1} J_{x} \cdot\left[\sum_{y=1}^{4} A_{y} \cdot\left(1-R_{x, y}\right)\right]$,

where $x$ is a given particle size discretized into $n$ bins (two bins for petroleum and three bins for coal and biomass), $y$ is a specific control device (cyclone, scrubber, electrostatic precipitator, or no control), $a$ is the consumption of fuel, $b$ is the completeness of combustion (defined as the fraction of fuel burnt in the fires), $c$ is the Fe content of the fuel, $f$ is the fraction of Fe retained in residue ash relative to the amount of Fe in burnt fuel, $J_{x}$ is the fraction of Fe emitted in particle 
size $x$, the $A_{y}$ is the fraction of a specific control device, and $R_{x, y}$ is the removal efficiency of control device $y$ for particle size $x$. For all parameters in Eq. (1), the values or ranges are listed in Table 1 and briefly described below. The $\mathrm{Fe}$ in coal fly ash was divided into three size bins: $0.1-0.3 \%$ in $\mathrm{PM}_{1}$ (diameter $<1 \mu \mathrm{m}$ ), $10-30 \%$ in $\mathrm{PM}_{1-10}$ (diameter 1-10 $\mu \mathrm{m}$ ), and the remainder in $\mathrm{PM}_{>10}$ (diameter $\left.>10 \mu \mathrm{m}\right)($ Querol et al., 1995; Yi et al., 2008). The Fe in biomass fly ash was also divided into three size bins: $1-3 \%$ in $\mathrm{PM}_{1}, 50-60 \%$ in $\mathrm{PM}_{1-10}$, and the remainder in $\mathrm{PM}_{>} 10$ (Latva-Somppi et al., 1998; Valmari et al., 1999). The Fe in oil fly ash was divided into two size bins: $80-95 \%$ in $\mathrm{PM}_{1}$ and the remainder in $\mathrm{PM}_{1-10}$ (Mamane et al., 1986; Kittelson et al., 1998). Fuel consumption data are distributed spatially at a $0.1^{\circ} \times 0.1^{\circ}$ resolution in PKU-FUEL-2007 (Wang et al., 2013), established for year 2007, combined with country data to obtain temporal changes from 1960 to 2006 (Chen et al., 2014; Wang et al., 2014a). Fixed completeness of combustion (b) values were assigned to coal $(98 \%)$, petroleum $(98 \%)$, wood in stoves $(88 \%)$, wood in fireplaces $(79 \%)$ and crop residues (92\%) (Johnson et al., 2008; Lee et al., 2005; Zhang, et al., 2008). As the fuel consumptions for biomass burning have already accounted for the completeness of combustion based on the type of fires (van der Werf et al., 2010), we applied a combustion completeness of $100 \%$ for them. The percentage of each control device $\left(A_{y}\right)$ was calculated by year and country in our previous studies (Chen et al., 2014; Wang et al., 2014a, b) using a method based on S-shaped curves (Grubler et al., 1999; Bond et al., 2007).

\subsection{Fe content in fuel}

Fe content in coal was derived for 45 major coal-producing countries, such as China, US, Russia, India, Indonesia and Australia, from the World Coal Quality Inventory (Tewalt et al., 2010), which is based upon 1379 measured data in each country. The collected Fe content in coal followed lognormal distributions (Supplement Fig. S1), and the means and standard deviations $(\sigma)$ of $\log _{10}$-transformed Fe content in coal were derived for each country (Table S1). Fe content of coal burned in each country was then calculated including imported coal using the coal-trading matrix among countries (Chen et al., 2014). The variation of $\mathrm{Fe}$ content among different coal types (which differs by $20 \%$ between bituminous coal and lignite produced in Turkey as an example) is smaller than that of coal produced in different countries and is thus ignored in our study. In addition to coal, Fe contents of wood, grass, and crop residues were taken from a review study (Vassilev et al., 2010), also following log-normal distributions (Fig. S1). The means and $\sigma$ of the $\log _{10}$-transformed Fe contents were thereby derived for wood, grass, and crop residues separately. We applied the Fe content in grass $(-3.57 \pm 0.34$ for $\log _{10}$-transformed $\mathrm{Fe}$ content) for the savanna and grassland fires and the $\mathrm{Fe}$ content in wood $(-3.45 \pm 0.57)$ for the deforestation, forest, woodland and peat fires. In addi- tion, the means and $\sigma$ of $\mathrm{Fe}$ contents were $0.13 \pm 0.09 \%$ for dung cakes (Sager et al., 2007) and $0.00024 \pm 0.00023 \%$ for biodiesel (Chaves et al., 2011), $32 \pm 2 \mathrm{ppm}$ for fuel oil (Bettinelli et al., 1995), $13 \pm 7 \mathrm{ppm}$ for diesel, $3.3 \pm 2.6 \mathrm{ppm}$ for gasoline and $4.9 \pm 3.3 \mathrm{ppm}$ for liquefied petroleum gas (Kim et al., 2013).

\subsection{Partitioning of $\mathrm{Fe}$ in combustion}

The fraction of Fe retained in residue ash ( $f$ in Eq. 1) during coal combustion has been measured for few real-world facilities: $43-45 \%$ in a power plant in India (Reddy et al., 2005), $30 \%$ in a power plant equipped with a bag-house in China (Yi et al., 2008), $40 \%$ in a fluidized bed boiler (Font et al., 2012), and 30-40\% (measured for Mn, which is similar to $\mathrm{Fe}$ ) in two power plants in China (Tang et al., 2013). We therefore applied a percentage of 30-45\% for Fe retained in residue ash during the combustion of coal in industry and power plants. For the combustion of petroleum, 43 and $58 \%$ of the $\mathrm{Fe}$ in petroleum in a small-fire-tube boiler and a combustor representative for a larger utility boiler, respectively, were emitted in fly ash (Linak and Miller, 2000). A range of $43-58 \%$ was thus adopted for $\mathrm{Fe}$ emitted into fly ash for petroleum burned in power plants and industry. For solid biofuels burned in industry, $60-70 \%$ of the Fe was retained in the residue ash (Ingerslev et al., 2011; Narodoslawsky et al., 1996), which was the range adopted in this study.

The budget of $\mathrm{Fe}$ from the combustion of petroleum by motor vehicles has received little attention, likely due to the low Fe content in petroleum. Wang et al. (2003) reported that $93 \% \mathrm{Fe}$ in petroleum was released into the atmosphere, and thus we applied a percentage of $93 \pm 5 \%$ for Fe emitted into the atmosphere.

The partitioning of Fe from the combustion of various fuels in the residential sector has not been studied. The concentrations of $\mathrm{Fe}$ in residue ash and fly ash are similar (Meij, 1994), so the fraction of Fe emitted into the atmosphere was derived from the ratio of the mass of Fe in fly ash to that in the fuel. We thereby derived the fraction of $\mathrm{Fe}$ retained in residue ash ( $f$ in Eq. 1) from the burning of anthracite coal $(99.6 \pm 0.4 \%)$ (Chen et al., 2006; Shen et al., 2010), bituminous coal (94 $\pm 3 \%$ ) (Chen et al., 2006; Shen et al., 2010 ), crop residues $(87 \pm 8 \%)$ (Li et al., 2007), and wood (94 $\pm 5 \%$ ) (Shen et al., 2012) burned in residential stoves or fireplaces.

Many studies measured the budget of elements other than $\mathrm{Fe}$ in the open burning of biomass. We collected the budget measured for elements whose physical and chemical properties are similar to those for $\mathrm{Fe}$ (e.g. low volatility). In the literature, the percentage of the element transfer to the atmosphere based on the element present in initial fuels was converted to that based on that in burnt fuels using the completeness of combustion (Raison et al., 1985; Pivello and Coutinho, 1992; Mackensen et al., 1996; Holscher et al., 1997). Raison et al. (1985) reported that $44-59 \%$ of the 
Table 1. Parameters used in the estimation of $\mathrm{Fe}$ emissions from combustion sources.

\begin{tabular}{|c|c|c|}
\hline Parameter & Description & Values or data sources \\
\hline$a$ & Fuel consumption & $\begin{array}{l}\text { The fuel data was taken from a global } 0.1^{\circ} \times 0.1^{\circ} \text { fuel data set which is used } \\
\text { to construct a global } \mathrm{CO}_{2} \text { emission inventory } \\
\text { (Wang et al., 2013; available at http://inventory.pku.edu.cn/home.html). }\end{array}$ \\
\hline$b$ & Completeness of combustion & $\begin{array}{l}\text { - coal }(98 \%) \\
\text { - petroleum }(98 \%) \text {; } \\
\text { - wood in stoves }(88 \%) \\
\text { - wood in fireplaces }(79 \%) \\
\text { - crop residues }(92 \%) \\
\text { - biomass burning (considered in van der Werf et al., 2010). }\end{array}$ \\
\hline$c$ & Fe content of the fuel & $\begin{array}{l}\text { - coal: based on Fe contents in coal produced by country (Table S2) and an } \\
\text { international coal-trading matrix Chen et al. (2014); } \\
\text { - wood (a geometric mean of } 0.036 \% \text { and range in Fig. S1); } \\
\text { - crop residues (a geometric mean of } 0.060 \% \text { and range in Fig. S1); } \\
\text { - grass (a geometric mean of } 0.027 \% \text { and range in Fig. S1); } \\
\text { - dung cakes }(0.13 \pm 0.09 \%) ; \\
\text { - biodiesel }(0.00024 \pm 0.00023 \%) \\
\text { - heavy fuel oil }(32 \pm 2 \mathrm{ppm}) \text {; } \\
\text { - diesel ( } 13 \pm 7 \mathrm{ppm}) \\
\text { - gasoline }(3.3 \pm 2.6 \mathrm{ppm}) ; \\
\text { - liquefied petroleum gas }(4.9 \pm 3.3 \mathrm{ppm})\end{array}$ \\
\hline$f$ & $\begin{array}{l}\text { Fraction of Fe retained in residue ash relative } \\
\text { to the amount of } \mathrm{Fe} \text { in the burnt fuel }\end{array}$ & $\begin{array}{l}\text { - coal used in industry and power plants }(30-45 \%) ; \\
\text { - petroleum used in industry and power plants }(43-58 \%) ; \\
\text { - solid biofuels used in industry and power plants }(60-70 \%) \text {; } \\
\text { - petroleum consumed by motor vehicles }(2-12 \%) ; \\
\text { - anthracite coal used in the residential sector }(99.2-99.8 \%) ; \\
\text { - bituminous coal used in the residential sector }(91-97 \%) ; \\
\text { - crop residues used in the residential sector }(79-95 \%) ; \\
\text { - wood used in the residential sector }(89-99 \%) ; \\
\text { - forest fires }(49-98 \%) ; \\
\text { - savanna fires }(24-79 \%) \text {; } \\
\text { - deforestation }(43-50 \%) ; \\
\text { - woodland fires/peat fires }(41-56 \%) \text {. }\end{array}$ \\
\hline$J_{x}$ & Fraction of Fe emitted in a particle size & $\begin{array}{l}\text { - coal fly ash }\left(0.1-0.3 \% \text { in } \mathrm{PM}_{1} ; 10-30 \% \text { in } \mathrm{PM}_{1-10} \text {; the remainder in } \mathrm{PM}_{>10}\right) \text {; } \\
\text { - oil fly ash }\left(80-95 \% \text { in } \mathrm{PM}_{1} ; \text { the remainder in } \mathrm{PM}_{1-10}\right) \text {; } \\
\text { - biomass fly ash }\left(1-3 \% \text { in } \mathrm{PM}_{1} ; 50-60 \% \text { in } \mathrm{PM}_{1-10} \text {; the remainder in } \mathrm{PM}_{>10}\right) \text {. }\end{array}$ \\
\hline$A_{y}$ & Fraction of a specific control device & $\begin{array}{l}A_{y} \text { is computed for each country and each year using a function by Grubler et al. (1999) } \\
\text { and Bond et al. (2007): } A_{y}=\left(F_{0}-F_{f}\right) \exp \left[-\left(t-t_{0}\right)^{2} / 2 s^{2}\right]+F_{f} \text {, where } F_{0} \text { and } F_{f} \text { are } \\
\text { the initial and final fractions of the technology, } t_{0} \text { is transition beginning time, and } s \text { is } \\
\text { transition rate. Parameters were determined for developing or developed countries and } \\
\text { listed in Wang et al. (2014a). }\end{array}$ \\
\hline$R_{x, y}$ & $\begin{array}{l}\text { Removal efficiency for each particle size by } \\
\text { different control device Zhao et al. (2008) }\end{array}$ & $\begin{array}{l}\text { - cyclone }\left(10 \% \text { for } \mathrm{PM}_{1} ; 70 \% \text { for } \mathrm{PM}_{1-10} ; 90 \% \text { for } \mathrm{PM}_{>10}\right) \\
\text { - scrubber }\left(50 \% \text { for } \mathrm{PM}_{1} ; 90 \% \text { for } \mathrm{PM}_{1-10} ; 99 \% \text { for } \mathrm{PM}_{>10}\right) \\
\text { - electrostatic precipitator }\left(93.62 \% \text { for } \mathrm{PM}_{1} ; 97.61 \% \text { for } \mathrm{PM}_{1-10} ; 99.25 \% \text { for } \mathrm{PM}_{>10}\right)\end{array}$ \\
\hline
\end{tabular}

manganese in burnt fuel was transferred to the atmosphere in three prescribed vegetation fires $(f=41-56 \%)$. Pivello and Coutinho (1992) reported that $63 \%$ of the potassium, $76 \%$ of the calcium and $61 \%$ of the magnesium in burnt fuel were transferred to the atmosphere in a Brazilian savanna fire ( $f=24-39 \%)$. Mackensen et al. (1996) reported that 18$51 \%$ of the potassium in burnt fuel was transferred to the atmosphere for two plots of forest fires in eastern Amazonia ( $f=49-82 \%$ ). Holscher et al. (1997) reported that $50 \%$ of the calcium and $57 \%$ of the magnesium in burnt fuel was transferred to the atmosphere during a deforestation fire in
Brazil ( $f=43-50 \%$ ). Laclau et al. (2002) reported that $61 \%$ of the potassium, $79 \%$ of the calcium and $72 \%$ of the magnesium were bound in residue ash in the complete combustion of leaf litter from the littoral savannas of Congo $(f=61-$ $79 \%$ ). Chalot et al. (2012) reported that $70 \%$ of the copper and $55 \%$ of the zinc in all combustion products were bound in residue ash in the combustion of phytoremediated wood ( $f=55-70 \%)$. In summary, we assumed that the partitioning of $\mathrm{Fe}$ is similar to these analogue elements, and applied a fraction of $\mathrm{Fe}$ in residue ash in burnt fuel $(f)$ of $49-82 \%$ for forest fires (Mackensen et al., 1996; Chalot et al., 2012), 
24-79\% for savanna fires (Pivello and Coutinho, 1992; Laclau et al., 2002), 43-50\% for deforestation (Holscher et al., 1997), and $41-56 \%$ for woodland and peat fires (Raison et al., 1985). Here, the percentage of Fe transferred to the atmosphere for biomass burning in the field is larger than that in the residential stoves (see values above) and this is likely due to the wind which can uplift more combustion ashes into the air in the case of wildfires (Pivello and Coutinho, 1992).

\subsection{Spatial allocation of Fe emissions from combustion}

Iron emissions from combustion sources were allocated to $0.1^{\circ} \times 0.1^{\circ}$ grids for 2007 and to $0.5^{\circ} \times 0.5^{\circ}$ grids for 1960 2006. The annual emissions of $\mathrm{Fe}$ were estimated based on the $0.1^{\circ}$ gridded fuel data which is used to construct a global $\mathrm{CO}_{2}$ emission inventory (Wang et al., 2013; available at http://inventory.pku.edu.cn/home.html) and on countryspecific parameters for 2007. For other years, Fe emissions from fossil fuels and biofuel were first calculated at the national level and then allocated to $0.5^{\circ}$ grids by sector (energy, residential, transportation, and industry) using the emission distribution of black carbon (BC) in each year for the same sector from the MACCity inventory (Lamarque et al., 2010; Granier et al., 2011) as a proxy. Gridded emissions from wildfires were estimated from carbon emission data at a resolution of $0.5^{\circ} \times 0.5^{\circ}$ compiled by GFED3 (Global Fire Emissions Database version 3) (van der Werf et al., 2010) for 1997-2007 and by RETRO (REanalysis of the TROpospheric chemical composition over the past 40 years) for 1960-1996 (Schulz et al., 2008). RETRO does not provide data for deforestation fires separately, so that the average fractions of deforestation fires in total forest fires by GFED3 were applied for 1960-1996.

\subsection{Uncertainty of $\mathrm{Fe}$ emissions from combustion}

A Monte Carlo ensemble simulation was run 1000 times by randomly varying parameters in the model, including fuel consumption, the $\mathrm{Fe}$ content, the fraction of $\mathrm{Fe}$ retained in the residue ash, the size distribution of $\mathrm{Fe}$ emission and the technology division of control device. Normal (petroleum, biodiesel, and dung cake) or log-normal (coal, grass, wood, and crop residues) distribution was adopted for the Fe content of fuel, as described above. The fraction of Fe retained in the residual ash was assumed to be uniformly distributed with ranges summarized in Sect. 2.3. Uncertainties in the fuelconsumption data and the technology divisions were quantified by prescribing a uniform distribution with a fixed relative standard deviation, as introduced in the previous studies (Wang et al., 2013, 2014a; Chen et al., 2014).

\subsection{Emissions of Fe from mineral sources}

We estimated the content of $\mathrm{Fe}$ in dust based on the largest mineralogical database to date (Journet et al., 2014). Journet et al. (2014) provided global $0.5^{\circ} \times 0.5^{\circ}$ maps for six types of Fe-containing minerals (illite, smectite, kaolinite, chlorite, vermiculite and feldspars) and two types of $\mathrm{Fe}$ oxides (hematite and goethite) in the clay $(<2.0 \mu \mathrm{m})$ and only goethite in the silt $(>2.0 \mu \mathrm{m})$ fraction. Then, a global $0.5^{\circ} \times 0.5^{\circ}$ map of $\mathrm{Fe}$ content in clay fraction was obtained (Fig. S2) with the Fe content of each mineral (4.3\% for illite, $2.6 \%$ for smectite, $0.23 \%$ for kaolinite, $12.5 \%$ for chlorite, $6.7 \%$ for vermiculite, $0.34 \%$ for feldspars, $62.8 \%$ for goethite and $69.9 \%$ for hematite) measured in Journet et al. (2008) and compiled in Journet et al. (2013). Note that we only account for the variation of dust emissions when assessing the uncertainty in Fe emissions from dust. However, there is also a variation of elemental composition of minerals in nature. For example, the Fe content can vary from 0.8 to $8.4 \%$ in illite depending on the environmental condition (Murad and Wagner, 1994), and from 0.02 to $0.81 \%$ in kaolinite (Mestdagh et al., 1980). This uncertainty is not accounted for in our study due to lack of a global distribution of elemental composition in minerals. Finally, the LMDz-INCA global model (Sect. 2.7) was run for 2000-2011 at a resolution of $0.94^{\circ}$ latitude by $1.28^{\circ}$ longitude to produce an averaged field of dust emissions.

\subsection{Modelling the atmospheric transport and deposition of $\mathrm{Fe}$ aerosols}

We used the LMDz-INCA global chemistry-aerosolclimate model coupling on-line the LMDz (Laboratoire de Météorologie Dynamique, version 4) General Circulation Model (Hourdin et al., 2006) and the INCA (INteraction with Chemistry and Aerosols, version 4) model (Hauglustaine et al., 2004; Schulz, 2007; Balkanski, 2011) to simulate the atmospheric transport and distributions of $\mathrm{Fe}$ emitted from combustion and mineral sources. The interaction between the atmosphere and the land surface is ensured through the coupling of LMDz with the ORCHIDEE (ORganizing Carbon and Hydrology In Dynamic Ecosystems, version 9) dynamical vegetation model (Krinner et al., 2005). In the present configuration, the model was run at a horizontal resolution of $0.94^{\circ}$ latitude by $1.28^{\circ}$ longitude with 39 vertical layers from the surface to $80 \mathrm{~km}$. In all simulations, meteorological data from the European Centre for Medium-Range Weather Forecasts (ECMWF) reanalysis have been used. The relaxation of the GCM winds towards ECMWF meteorology was performed by applying at each time step a correction term to the GCM predicted $u$ and $v$ wind components with a relaxation time of $6 \mathrm{~h}$ (Hourdin and Issartel, 2000; Hauglustaine et al., 2004). The ECMWF fields are provided every $6 \mathrm{~h}$ and interpolated onto the LMDz grids.

In the model, the emissions of dust were calculated as a function of wind velocities at a height of $10 \mathrm{~m}$ (with a threshold value) and of the clay content from dust source locations (Schulz et al., 1998; Balkanski et al., 2007). The simulated concentrations and optical depths of dust have been validated by measurements (Schulz et al., 1998; Guelle et al., 2000; 
Balkanski et al., 2004, 2007). For transport, the model uses a computationally efficient scheme to represent the size distribution of dust. The tracer is treated as a log-normal distribution with a mass median diameter (MMD) and a fixed geometric $\sigma$ (defined as the $\sigma$ of log-transformed sizes). Hygroscopic growth and removal processes are assumed to affect the MMD rather than the width of the distribution (Schulz et al., 1998, 2007). After being emitted, dust with a MMD of $2.5 \mu \mathrm{m}$ and a geometric $\sigma$ of 2.0 is transported and removed by sedimentation (Slinn and Slinn, 1980), wet and dry deposition (Balkanski et al., 2004, 2010; Balkanski, 2011).

The emitted Fe from combustion sources were partitioned into three particulate modes with the following characteristics: $\mathrm{Fe}$ in $\mathrm{PM}_{1}$ as a fine mode $(\mathrm{MMD}=0.34 \mu \mathrm{m}$, geometric $\sigma=1.59$ ); $\mathrm{Fe}$ in $\mathrm{PM}_{1-10}$ as a coarse mode (MMD $=3.4 \mu \mathrm{m}$, geometric $\sigma=2.0$ ); $\mathrm{Fe}$ in $\mathrm{PM}_{>} 10$ as a super-coarse mode (MMD $=34.0 \mu \mathrm{m}$, geometric $\sigma=2.0$ ) (Mamane et al., 1986; Querol et al., 1995; Valmari et al., 1999). Hygroscopic growth, sedimentation, dry and wet deposition accounted for $\mathrm{Fe}$ in $\mathrm{PM}_{1-10}$ and $\mathrm{PM}_{>10}$, as for dust, and $\mathrm{Fe}$ in $\mathrm{PM}_{1}$ as for BC (Balkanski et al., 2004, 2010; Balkanski, 2011). Hygroscopic growth of particles in the model is treated as a function of ambient relative humidity and the composition of soluble aerosol components based on Gerber's experiment work (Gerber, 1988). The uptake of water on aerosols increases the particle size of Fe, while the loss of water on aerosols decreases the particle size of Fe. For the particle density, the fraction of low density mass in coal fly ash is found to increase with decreasing particle size (Furuya et al., 1987). The major fraction for particles with a diameter less than $10 \mu \mathrm{m}$ is composed by mass with a density of $2.4-2.8 \mathrm{~g} \mathrm{~cm}^{-3}$, and by mass with a density of $1.6-2.4 \mathrm{~g} \mathrm{~cm}^{-3}$ for particles with a diameter from 10 to $100 \mu \mathrm{m}$. Therefore, we applied a density of 2.6 and $2.0 \mathrm{~g} \mathrm{~cm}^{-3}$ for Fe transported in $\mathrm{PM}_{1-10}$ and $\mathrm{PM}_{>10}$ respectively in the model. For $\mathrm{Fe}$ in $\mathrm{PM}_{1}$, we assumed that the density is the same as $\mathrm{BC}\left(1.5 \mathrm{~g} \mathrm{~cm}^{-3}\right)$. For the hygroscopic properties of $\mathrm{Fe}$, it is found that $\mathrm{Fe}$ in large-size coal ash is dominated in aluminosilicate glass, similar to that in dust (Chen et al., 2012), and thus we assume that the Fe in $\mathrm{PM}_{1-10}$ and $\mathrm{PM}_{>10}$ can be treated as insoluble dust, which is removed by sedimentation, dry deposition and below-cloud scavenging. For the $\mathrm{Fe}$ in $\mathrm{PM}_{1}$, it is found that approximately $25 \%$ of $\mathrm{Fe}$ in fine particle (diameter $<0.61 \mu \mathrm{m}$ ) is bound to organic matter and is thus insoluble (Espinosa et al., 2002). Thus, we assumed that $25 \%$ of $\mathrm{Fe}$ in $\mathrm{PM}_{1}$ was hydrophobic, which is removed by sedimentation, dry deposition and below-cloud scavenging, but not by in-cloud scavenging. The remainder $\mathrm{Fe}$ in $\mathrm{PM}_{1}$ was hydrophilic, which is removed by sedimentation, dry deposition, below-cloud scavenging and in-cloud scavenging. Due to limited understanding of the heterogeneous chemistry of $\mathrm{Fe}$ in the cloud, we did not account for the conversion of Fe from hydrophobic to hydrophilic in the atmospheric transport, and the ratio between the two phases varies due to their different removal rates in the atmosphere.
Running the model for the whole period 1990-2007 was too heavy computationally. Therefore, we ran the model for one representative year. We plan to run the simulations for more years for a future study. In the present study, simulations were run for a typical year (2005) for the Fe emitted from the combustion of coal (three size classes), petroleum (two size classes) and biomass (three size classes). The Fe emitted from combustion as monthly means averaged over 1990-2007 were used as an input to the model, which produces the distribution of $\mathrm{Fe}$ concentrations attached to aerosols in the surface layer of the atmosphere contributed by combustion sources. When evaluating the modelled Fe concentrations by observations, we added the Fe concentrations contributed by combustion sources and dust together. However, there is a notable temporal variation of the combustionrelated emissions over this period. The coefficient of variation (defined as the standard deviation relative to the mean) of annual Fe emissions from combustion over 1990-2007 is 46, 28, 17, 22, 26 and $22 \%$ for Europe, North America, South America, Africa, Asia and Oceania, respectively. To account for the impact of the changing emissions, when comparing the model with observations, we scaled the modelled Fe concentration from combustion at each land site by the ratio of the national $\mathrm{Fe}$ emission in the year to the 1990-2007 average in the country, and then compare it with the measured concentrations. For sites in the oceans, we scaled the concentrations following the same method using the global total emissions. In addition, since the change of land use during the period has not been accounted for when estimating the dust emissions in the model, we used the average Fe concentration by dust over 2000-2011 when comparing against observations and estimating the average contribution to $\mathrm{Fe}$ concentrations by different sources. Therefore, uncertainties induced by the nonlinearity of $\mathrm{Fe}$ concentrations to emissions and the interannual variation of dust emissions have not been accounted for in our study, which should be notified when comparing the model against the observations.

\section{Emission sources of $\mathrm{Fe}$}

\subsection{Emissions of Fe from combustion}

Based on the fuel consumptions and $\mathrm{Fe}$ emission rates, the average of global $\mathrm{Fe}$ emissions for 1960-2007 was $5.3 \mathrm{Tg} \mathrm{yr}^{-1}$ from combustion sources, with 0.046, 1.4 and $3.8 \mathrm{Tg} \mathrm{yr}^{-1}$ of $\mathrm{Fe}$ emitted in $\mathrm{PM}_{1}, \mathrm{PM}_{1-10}$ and $\mathrm{PM}_{>10}$, respectively. The Monte Carlo simulation of emission parameters shows that the $\mathrm{Fe}$ emissions were log-normally distributed (Fig. 1). The $\sigma$ of $\log _{10}$-transformed Fe emissions $\left(\log _{10} \sigma\right)$ was 0.22 for the global total, corresponding to a $90 \%$ confidence range of 2.3 to $12.1 \mathrm{Tg} \mathrm{yr}^{-1}$, or -56 to $+128 \%$ relative to the central estimate. In addition, the $\log _{10} \sigma$ varied from 0.09 (petroleum) to 0.27 (coal) for the emissions from different fuels (Fig. 1a). Due to a relatively 
Table 2. Comparison of $\mathrm{Fe}$ emissions from combustion and mineral sources $\left(\mathrm{Tg} \mathrm{yr}^{-1}\right)$ in the present work and previous studies. The uncertainty range in our estimate is given in parentheses as a $90 \%$ confidence interval from a Monte Carlo simulation (1000 runs). The Fe content of dust used to estimate $\mathrm{Fe}$ emissions from mineral sources $\left(F_{\mathrm{c}}\right)$ is indicated for each estimate.

\begin{tabular}{|c|c|c|c|c|}
\hline Study & Year (s) & Fossil fuels & Biomass & Mineral sources \\
\hline Bertine and Goldberg (1971) & 1967 & 1.4 (all sizes) & & \\
\hline Luo et al. (2008) & 1996 & $\begin{array}{l}0.56\left(\mathrm{PM}_{1-10}\right) \\
0.10\left(\mathrm{PM}_{1}\right)\end{array}$ & $\begin{array}{l}0.86\left(\mathrm{PM}_{1-10}\right) \\
0.21\left(\mathrm{PM}_{1}\right)\end{array}$ & $55\left(F_{\mathrm{c}}=3.5 \%\right)$ \\
\hline Ito (2013) & 2001 & $\begin{array}{l}0.44\left(\mathrm{PM}_{1-10}\right) \\
0.07\left(\mathrm{PM}_{1}\right)\end{array}$ & $\begin{array}{l}0.92\left(\mathrm{PM}_{1-10}\right) \\
0.23\left(\mathrm{PM}_{1}\right)\end{array}$ & $74\left(F_{\mathrm{c}}=3.5 \%\right)$ \\
\hline Present study & $\begin{array}{l}1967 \\
1996 \\
2001 \\
2000-2011 \\
2000-2011\end{array}$ & $\begin{array}{l}3.0(1.2-7.2) \text { (all sizes) } \\
1.1(0.54-2.4)\left(\mathrm{PM}_{1-10}\right) \\
0.036(0.022-0.060)\left(\mathrm{PM}_{1}\right) \\
0.83(0.40-1.7)\left(\mathrm{PM}_{1-10}\right) \\
0.035(0.022-0.058)\left(\mathrm{PM}_{1}\right)\end{array}$ & $\begin{array}{l}0.46(0.16-1.27)\left(\mathrm{PM}_{1-10}\right) \\
0.017(0.006-0.046)\left(\mathrm{PM}_{1}\right) \\
0.46(0.16-1.26)\left(\mathrm{PM}_{1-10}\right) \\
0.017(0.006-0.046)\left(\mathrm{PM}_{1}\right)\end{array}$ & $\begin{array}{l}38.5\left(F_{\mathrm{c}}=3.5 \%\right) \\
41.0\left(F_{\mathrm{c}} \text { using new }\right. \\
\text { mineralogical data })\end{array}$ \\
\hline
\end{tabular}
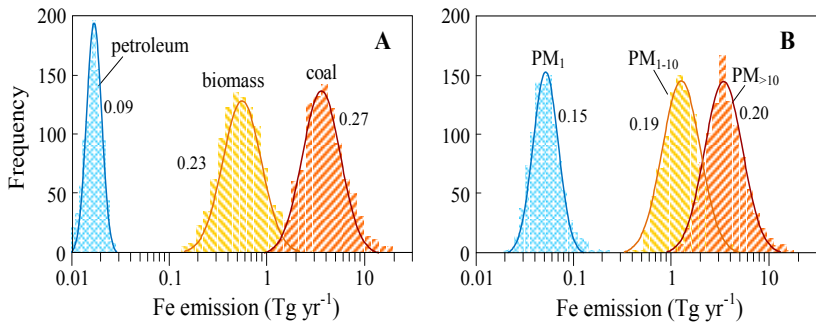

Figure 1. Frequency distributions of Fe emissions from different fuel types (a) and particle sizes (b). The distributions are derived from 1000 Monte Carlo simulations. The standard deviation of $\log _{10}$-transformed Fe emissions is shown for each distribution. The $x$-axis is plotted on a log scale.

large error in the Fe content of coal, the range of uncertainty of Fe emission from coal was larger than that of other fuels. Removing the variations of $\mathrm{Fe}$ content in fuel reduced the overall variation $\left(\log _{10} \sigma\right)$ of $\mathrm{Fe}$ emissions by $66 \%$ (coal), $34 \%$ (petroleum) and $50 \%$ (biomass). Consequently, a large contribution of uncertain $\mathrm{Fe}$ content in coal causes the range of uncertainty of $\mathrm{Fe}$ emissions in coarse particles to be larger than in fine particles (Fig. 1b). The uncertainty ranges in the estimated emissions from fossil fuels and biomass for selected years are listed in Table 2 .

The relative contributions of combustion sources to $\mathrm{Fe}$ emissions in different sizes are shown in Fig. 2. It shows that Fe emissions in medium-to-coarse particles $\left(\mathrm{PM}_{1-10}\right.$ or $\mathrm{PM}_{>10}$ ) are dominated by the combustion of coal in power plants and industry, followed by a notable contribution from the natural burning of biomass. By contrast, the combustion of petroleum (32\%), followed by coal (34\%) and biomass $(34 \%)$, contributed most to $\mathrm{Fe}$ emissions in fine particles
$\left(\mathrm{PM}_{1}\right)$. The different source profiles are important for determining the Fe solubility and are discussed in Sect. 7. For example, the observed solubility of Fe might be primarily controlled by the particle size of dust (Baker and Jickells, 2006), but also varies in the fly ash from different fuels (Schroth et al., 2009; Bowie et al., 2009; Chen et al., 2012).

\subsection{Spatial distributions of Fe emissions from combustion sources}

Fe emissions for 2007 from combustion in fine $\left(\mathrm{PM}_{1}\right)$ and medium-to-coarse $\left(\mathrm{PM}_{1-10}\right.$ and $\left.\mathrm{PM}_{>10}\right)$ particles are shown in Fig. 3. The spatial patterns were similar between Fe emitted in fine and medium-to-coarse particles, with high emission density in the populated regions of East Asia and South Asia, the industrialized regions of Europe and North America, and the frequently burned forests and savannas of South America and Africa. Some patterns, however, also differed between them regionally. For example, the $\mathrm{Fe}$ emission density of medium-to-coarse particles was much higher in Asia than in western Europe and eastern North America. By contrast, the Fe emission density of fine particles has similar high values among these regions, due to a large contribution by the burning of petroleum in motor vehicles and power plants in Europe and North America, and to low removal efficiency for fine particles in industry (Yi et al., 2008). Particularly, there was notable high Fe emission density in fine particles in the northern Atlantic and northern Pacific Oceans from shipping, which can contribute to soluble $\mathrm{Fe}$ in the water through local deposition. The emission density of $\mathrm{Fe}$ in $\mathrm{PM}_{1}$ is much lower than $\mathrm{Fe}$ in $\mathrm{PM}_{1-10}$ and $\mathrm{PM}_{>10}$, and but still important due to a higher solubility and longer lifetime in the transport (Baker and Jickells, 2006). 
$\mathbf{A}$

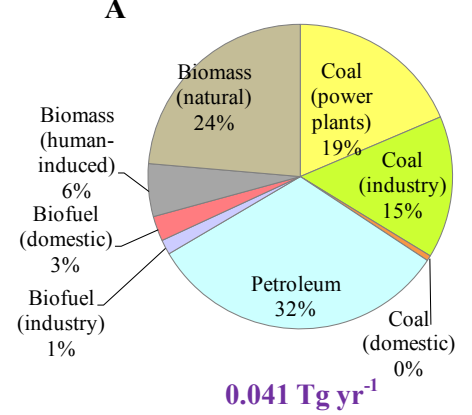

B

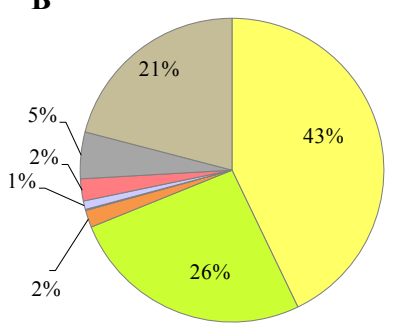

$1.3 \mathrm{Tg} \mathrm{yr}^{-1}$
C

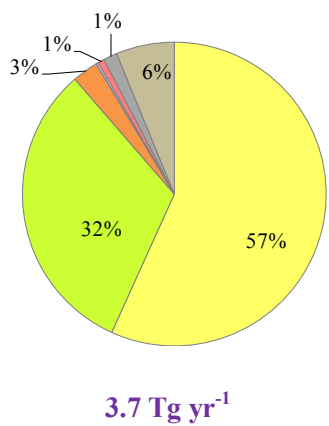

Figure 2. Source profiles of Fe from combustion for $\mathrm{PM}_{1}$ (a), $\mathrm{PM}_{1-10}(\mathbf{b})$, and $\mathrm{PM}_{>10}$ (c) as an average for 1960-2007. The total Fe emission for each size class is provided under its pie chart.
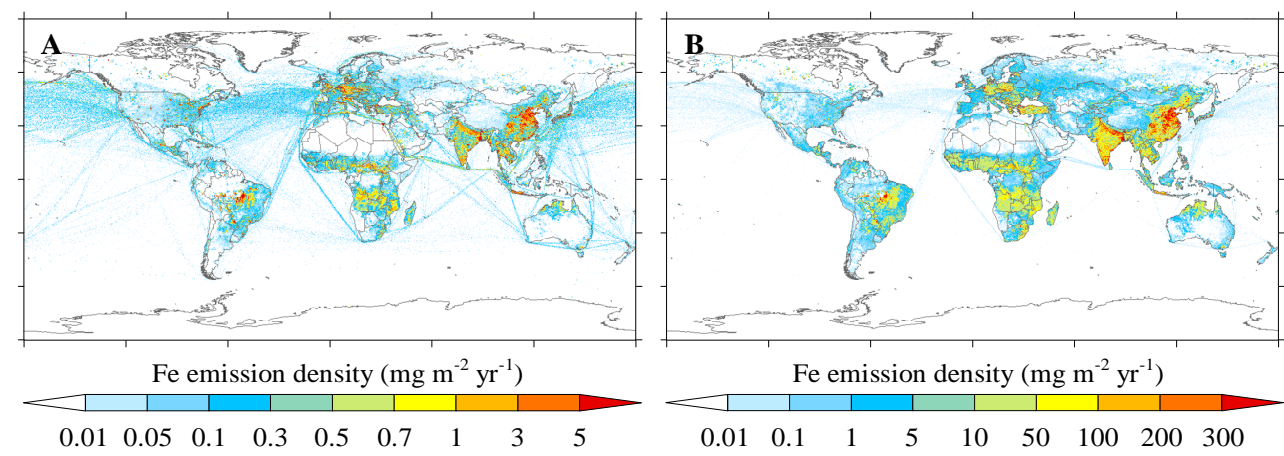

Figure 3. Spatial distributions of Fe emissions from combustion sources in 2007 at a resolution of $0.1^{\circ} \times 0.1^{\circ}$ for fine $\left(\mathrm{PM}_{1}\right)(\mathbf{a})$ and medium-to-coarse $\left(\mathrm{PM}_{1-10}\right.$ and $\left.\mathrm{PM}_{>10}\right)(\mathbf{b})$ particles.

\subsection{Temporal trends of Fe emissions from combustion sources}

The temporal changes of $\mathrm{Fe}$ emissions from combustion sources for 1960-2007 were derived for fine $\left(\mathrm{PM}_{1}\right)$ and medium-to-coarse $\left(\mathrm{PM}_{1-10}\right.$ and $\mathrm{PM}_{>}$10) particles (Fig. 4). Changes in both fuel consumption and control devices together control the temporal trends. For example, Fe emissions of both fine and medium-to-coarse particles had decreased since 1990 in Europe due to the switch from coal to gas and other sources of energy (i.e. solar and nuclear energy) (International Energy Agency, 2008), and also to policy regulations to implement emission control facilities (Vestreng et al., 2007). Similarly, the replacement of residential coal by petroleum or natural gas, and the implementation of policies enforcing control facilities around 1990 in China (Ministry of Environmental Protection of the People's Republic of China, 2008) together led to a slowdown or even a reversal of the increase of $\mathrm{Fe}$ emissions in the region.

The temporal trends of $\mathrm{Fe}$ emissions of fine and mediumto-coarse particles also notably differed. Before 1985, Fe emissions of fine and medium-to-coarse particles both increased, due to a rapid increase in fuel consumptions. After 1985, Fe emissions of fine particles first decreased and re-increased after 2000, while Fe emissions of medium-to- coarse particles continuously decreased. Two explanations can account for the decoupling. First, the control devices equipped in industry can remove $\mathrm{Fe}$ in medium-to-coarse particles more effectively than in fine particles (Yi et al., 2008). Second, the consumption of petroleum has been increasing in both developed and developing countries, sustaining fine-particle Fe emissions. In particular, Fe emission in fine particles in Asia had increased recently after a respite in the 1990s. The spatial distributions of Fe emissions from combustion sources from 1960 to 2007 are shown in Fig. S3. The emission centres have shifted from Europe and North America to Asia over the past five decades, in agreement with the trends shown in Fig. 4.

\subsection{Mineral sources of $\mathrm{Fe}$}

Based on the soil mineralogical data (Journet et al., 2014), the estimated global total emission of $\mathrm{Fe}$ from mineral sources ranged from 34.4 to $54.2 \mathrm{Tg} \mathrm{yr}^{-1}$ for $2000-2011$, with an average emission of $41.0 \mathrm{Tg} \mathrm{yr}^{-1}$. The modelled average global total emission of dust for 2000-2011 was $1040 \mathrm{Tg} \mathrm{yr}^{-1}$, close to the median of 14 AeroCom Phase I models (1120 $\mathrm{Tg} \mathrm{yr}^{-1}$ ) (Huneeus et al., 2011). Our estimated Fe emission from dust is lower than the $55-74 \mathrm{Tg} \mathrm{yr}^{-1}$ reported by Luo et al. (2008) and Ito (2013), mainly because 

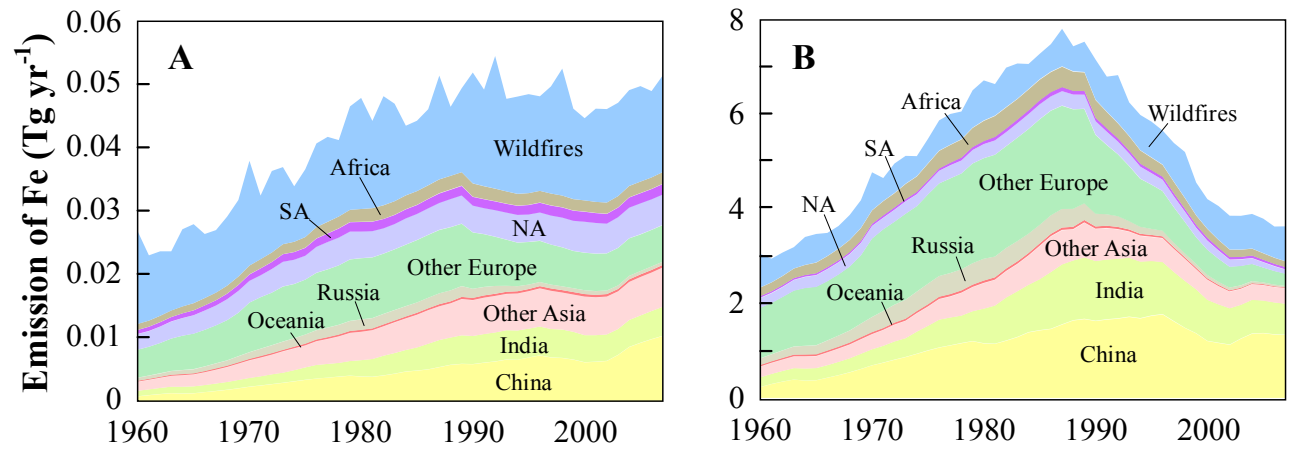

Figure 4. Temporal trends of $\mathrm{Fe}$ emissions of fine $\left(\mathrm{PM}_{1}\right)$ (a) and medium-to-coarse $\left(\mathrm{PM}_{1-10}\right.$ and $\mathrm{PM}_{>}$10) (b) particles from combustion sources from 1960 to 2007. Fe emissions from wildfires are shown separately with energy-related activities separated by region (NA for North America and SA for South America).
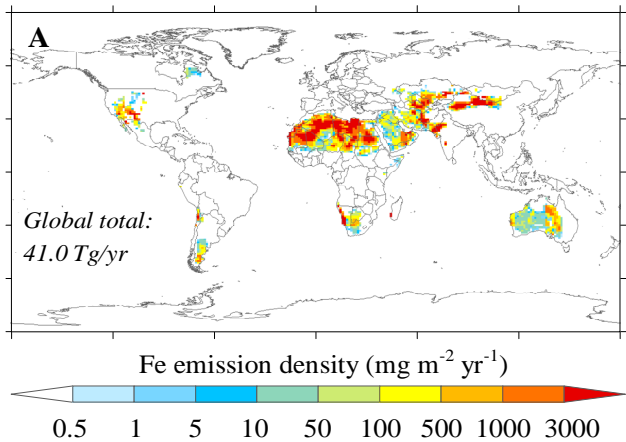

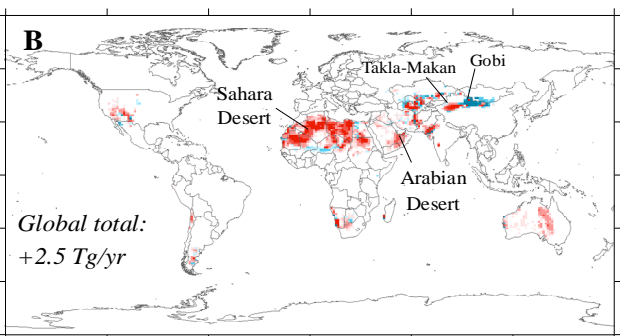

Fe emission density $\left(\mathrm{mg} \mathrm{m}^{-2} \mathrm{yr}^{-1}\right)$

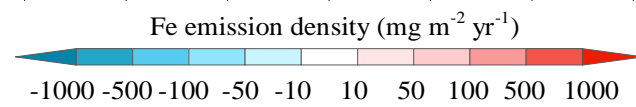

Figure 5. Average Fe emission from dust sources for 2000-2011 using the new mineralogical data set (a) and the difference of average Fe emission from dust sources for 2000-2011 using the new mineralogical data set relative to that using a constant Fe content (3.5\%) (b). A positive value in (b) indicates a larger emission density by using the new mineralogical data set.

the emission of dust is larger in the models used by these authors. For example, the model used by Luo et al. (2008)

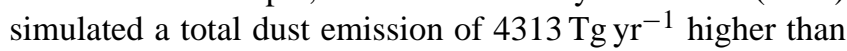
other 13 AeroCom Phase I models (Huneeus et al., 2011), including LMDz-INCA. However, the dust emission is very size-dependent, and the emissions should be evaluated by prescribing the size distribution in source regions to the transport models.

The average $\mathrm{Fe}$ emission density from mineral sources for 2000-2011 is mapped in Fig. 5a. The major source regions include the Sahara Desert, southern Africa, the Middle East, northwestern China, southwestern North America, southern South America, and western Australia. The estimated Fe emission map based on the new soil mineralogical data set (Journet et al., 2014) is also compared to that derived using a constant Fe content (3.5\%) (Fig. 5b) as measured by Taylor and McLennan (1985) and widely used in other models (Luo et al., 2008; Mahowald et al., 2009; Ito, 2013). The new mineralogical data set led to a larger Fe emission density over the Sahara, Arabian and Takla-Makan deserts, and a lower Fe emission density over the Gobi Desert, reflecting the difference of Fe content of dust relative to $3.5 \%$ (Fig. S2).

\subsection{Comparison of $\mathrm{Fe}$ emissions with previous studies}

Table 2 summarizes the comparison of our estimations of Fe emissions with previous studies (Bertine and Goldberg, 1971; Luo et al., 2008; Ito, 2013). Bertine and Goldberg (1971) estimated the emissions of 51 trace elements into the atmosphere from fossil fuel combustion $\left(1.4 \mathrm{Tg} \mathrm{yr}^{-1}\right.$ for 1967) based on a mass-balance method similar to ours. However, due to a lack of measurement data at the time, they assumed that $10 \%$ of all trace elements in fuels was transferred to the atmosphere. This rate is lower than the 30-45\% measured for Fe in recent studies (Yi et al., 2008; Font et al., 2012; Tang et al., 2013). The estimate by Bertine and Goldberg (1971) for the same year (1967) is within the uncertainty range of our estimate (1.2-7.2 $\mathrm{Tg} \mathrm{yr}^{-1}$ as $90 \%$ confidence), but half of our central estimate (3.0 $\mathrm{Tg} \mathrm{yr}^{-1}$ ) after accounting for different removal efficiencies by particle size and control device.

Luo et al. (2008) and Ito (2013) have estimated Fe emissions from the combustion of fossil fuels, biofuels and biomass burning in fine $\left(\mathrm{PM}_{1}\right)$ and medium particles $\left(\mathrm{PM}_{1-10}\right)$. Their estimates of the total $\mathrm{Fe}$ emissions (1.7 $\mathrm{Tg} \mathrm{yr}^{-1}$ for 1996 and 2001) are close to our central es- 
timates (1.6 for 1996 and $1.3 \mathrm{Tg} \mathrm{yr}^{-1}$ for 2001 with a $90 \%$ confidence range of $0.7-3.8$ and $0.6-3.1$, respectively). For fossil fuels, Luo et al. (2008) and Ito (2013) estimated Fe emissions based on the particle emission factors and the $\mathrm{Fe}$ contents of particles. Their estimates of fossil fuel emissions ( 0.51 for 1996 to $0.66 \mathrm{Tg} \mathrm{yr}^{-1}$ for 2001) are close to the lower bound in the uncertainty range of our estimates $(0.6-$ $2.5 \mathrm{Tg} \mathrm{yr}^{-1}$ as $90 \%$ confidence for 1996 and $0.4-1.8 \mathrm{Tg} \mathrm{yr}^{-1}$ for 2001) and lower than our central estimates (1.2 and $0.9 \mathrm{Tg} \mathrm{yr}^{-1}$ for the two years, respectively) for the same size class (Table 2). In the method used by Luo et al. (2008) and Ito (2013), the Fe contents of particles are measured in very few studies. For example, for coal burnt in power plants and industry, there are only three measurements in the USA which were used by Luo et al. (2008), reporting an Fe content of $4.5-7.6 \%$ in fine particles and $8.1-9.4 \%$ in coarse particles (Olmez et al., 1988; Smith et al., 1979; Mamane et al., 1986). In addition to large uncertainty in sample collection (Hildemann et al., 1989), the variation of $\mathrm{Fe}$ content in particles is large. The measured Fe content in coal fly ash generated by the combustion of bituminous coal in Shanxi Province, China is $10.2-11.9 \%$ (Fu et al., 2012), $40 \%$ higher than the values used by Luo et al. (2008) and Ito (2013). A larger Fe content than that used by Luo et al. (2008) and Ito (2013) was also found for oil/biofuel fly ashes in the measurement by Fu et al. (2012). The large variation of Fe content of particles explains part of the underestimation in the estimates by Luo et al. (2008) and Ito (2013). In addition, Luo et al. (2008) and Ito (2013) estimated that the Fe emission ratio between $\mathrm{PM}_{1}$ and $\mathrm{PM}_{1-10}$ is $1: 6$, compared to $1: 24$ in this study. The emission ratios used by Luo et al. (2008) and Ito (2013) were taken from Bond et al. (2004), which pertained to carbonaceous matter in fine particles but was not justified for $\mathrm{Fe}$ (mainly in coarse particles). For biomass burning, our central estimates of the total $\mathrm{Fe}$ emissions are lower than that by Luo et al. (2008) and Ito (2013). Luo et al. (2008) applied a globally constant $\mathrm{Fe}: \mathrm{BC}$ emission ratio based on the slope of $\mathrm{Fe}$ and $\mathrm{BC}$ concentrations observed for aerosols in the Amazon Basin. Note that the dust and plant material entrained in fires can contribute to the Fe concentrations in the atmosphere, as noticed by Luo et al. (2008). As a result, their estimates include the pyro-convection of $\mathrm{Fe}$ from soils and plant materials. In contrast, our estimate is based on the mass balance of $\mathrm{Fe}$ from the burnt fuels. This might explain partly why our estimate of the biomass burning emissions of $\mathrm{Fe}$ is lower than that in previous studies (Luo et al., 2008; Ito, 2013). Although our estimate provides an explicit source attribution of $\mathrm{Fe}$, which is useful for modelling the Fe solubility, it underestimates the total sources. We propose that the emissions of Fe by pyro-convection in the fires should be estimated separately in the future.

In a recent study focused on East Asia (Lin et al., 2015), the emission of $\mathrm{Fe}$ from combustion sources in East Asia in 2007 was estimated to be $7.2 \mathrm{Tg} \mathrm{yr}^{-1}$, far higher than all other studies (Luo et al., 2008; Ito, 2013) and the central es- timate in our study $\left(1.6 \mathrm{Tg} \mathrm{yr}^{-1}\right.$, with a $90 \%$ confidence of 0.66-3.84). The authors used an alternative method to estimate the emission of $\mathrm{Fe}$ based upon the sulfur dioxide $\left(\mathrm{SO}_{2}\right)$ emissions and the ratio of sulfur and $\mathrm{Fe}$ content in fuels. As pointed out by the authors, the emission of Fe from iron and steel industries is likely to be more important than previously thought. However, the authors also pointed out a notable uncertainty in their estimate because some parameters (e.g. the ratio of bottom ash to fly ash) are very uncertain due to the lack of measurements (Lin et al., 2015). The value taken for the ratio of bottom ash to fly ash in that study is from a single measurement that took place in Taiwan (Yen, 2011). Due to the lack of a sufficient number of measurements for some parameters, our method cannot be applied to estimate the global $\mathrm{Fe}$ emission from the individual sector of iron and steel industries. These remarks show that measurements are urgently needed to constrain the iron content of aerosols emitted from the iron and steel industries as well as other sectors.

\section{Modelling of Fe concentrations}

\subsection{Spatial distribution of Fe concentrations in surface air}

Based on the emissions of $\mathrm{Fe}$ from combustion sources as an average for 1990-2007 and mineral sources as an average for 2000-2011, the global distribution of annual mean Fe concentrations attached to aerosols in surface air was derived (Fig. 6).

Globally, Fe emissions were much higher from mineral sources $\left(41.0 \mathrm{Tg} \mathrm{yr}^{-1}\right)$ than from combustion sources $\left(5.3 \mathrm{Tg} \mathrm{yr}^{-1}\right)$. The modelled spatial distribution of Fe concentrations in surface air was thus dominated by mineral sources, in agreement with previous studies (Luo et al., 2008; Mahowald et al., 2009; Ito, 2013). Large Fe concentrations $\left(>1.0 \mu \mathrm{g} \mathrm{m}^{-3}\right)$ are simulated over northwestern Africa, southwestern North America, western China, the Middle East, southwestern Africa and central to northern Australia. In addition to these continent regions, large $\mathrm{Fe}$ concentrations $\left(>0.1 \mu \mathrm{g} \mathrm{m}^{-3}\right.$ ) are found over a large region of the Atlantic Ocean from 0 to $30^{\circ} \mathrm{N}$ due to the outflow of dust from the $\mathrm{Sa}-$ hara Desert, and large $\mathrm{Fe}$ concentrations $\left(>0.5 \mu \mathrm{g} \mathrm{m}^{-3}\right)$ are found over the Arabian Sea and the Indian Ocean due to the outflow of dust from the Arabian, Lut and Thar deserts.

\subsection{Evaluation of Fe concentrations in surface air}

The Fe concentrations attached to aerosols in surface air simulated for pixels of $0.94^{\circ}$ latitude by $1.28^{\circ}$ longitude were evaluated by 529 measurements obtained between 1990 to 2007. These measurements include data compiled by Mahowald et al. (2009) and Sholkovitz et al. (2012) and our collation of data from peer-reviewed studies (Table S2). The modelled $\mathrm{Fe}$ concentrations attached to aerosols in surface air, averaged for the months in the year of measurements, 


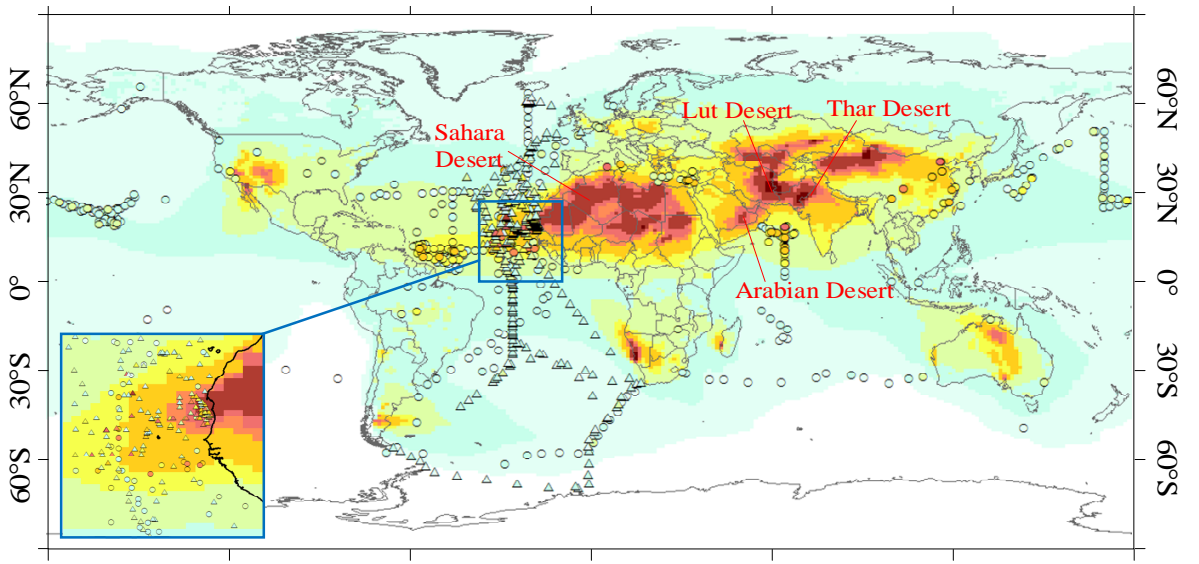

Fe concentration in surface air $\left(\mu \mathrm{g} \mathrm{m}^{-3}\right)$

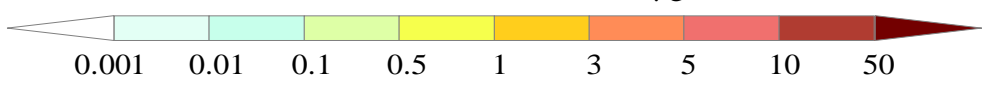

Figure 6. Distribution of annual mean concentrations of Fe attached to aerosols in surface air. A total of 529 measured Fe concentrations compiled by Mahowald et al. (2009) and Sholkovitz et al. (2012) and collected in this study (Table S3) are shown as circles, and a total of 296 Fe concentrations measured by Baker et al. (2013) over the Atlantic Ocean are shown as triangles.

Table 3. Statistics for the comparison of modelled and observed Fe concentrations. $N$, sample size; $F_{2}$ and $F_{5}$, fractions of stations with deviations within a factor of 2 or 5 , respectively; NMB, normalized mean bias. The values in parentheses show the indicators when the combustion sources are not included.

\begin{tabular}{lrrrr}
\hline & $N$ & $F_{2}(\%)$ & $F_{5}(\%)$ & NMB (\%) \\
\hline Indian Ocean & 61 & $30(30)$ & $75(75)$ & $-68(-68)$ \\
Atlantic Ocean & 224 & $64(63)$ & $83(79)$ & $15(14)$ \\
Pacific Ocean & 126 & $52(48)$ & $69(67)$ & $-66(-69)$ \\
South Ocean & 47 & $47(36)$ & $53(43)$ & $-44(-79)$ \\
East Asia & 32 & $84(13)$ & $100(31)$ & $-1.4(-78)$ \\
South America & 4 & $75(50)$ & $100(50)$ & $-73(-91)$ \\
North America & 12 & $83(33)$ & $100(67)$ & $-39(-66)$ \\
Mediterranean & 23 & $61(57)$ & $87(87)$ & $24(16)$ \\
\hline All regions & 529 & $57(49)$ & $78(70)$ & $-14(-32)$ \\
\hline
\end{tabular}

are plotted against the measured concentrations after scaling the $\mathrm{Fe}$ concentrations from combustion sources (Sect. 2.7; Fig. 7a). The simulated Fe concentrations were grouped into the same size range as measurements if the size was specified in the measurements; otherwise they were computed as total concentrations. The modelled spatial pattern matched the observations $\left(r^{2}=0.53\right)$. Mahowald et al. (2009) compared modelled annual mean Fe concentrations to measurements. They pointed out that the daily measurements from cruises are not as representative as the long-term station measurements. Similarly, a better agreement can be achieved if all cruise measurements are excluded in the comparison $\left(r^{2}=0.68\right)$ in our study (Fig. 7b).

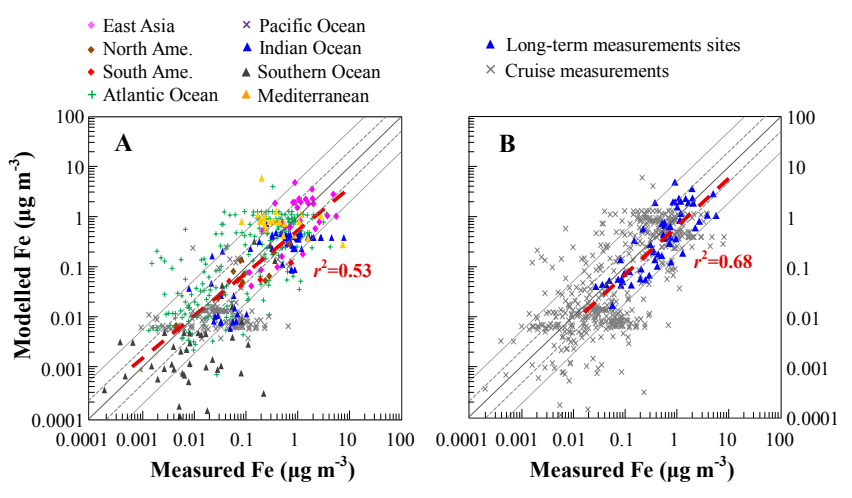

Figure 7. Comparisons of modelled and observed Fe concentrations by region (a) and measuring type (b). The modelled concentrations are averaged for the months in the year of measuring. The fitted curves for all stations in (a) and long-term measurement stations in (b) are shown as red dashed lines, with coefficients of determination $\left(r^{2}\right)$ listed. The $1: 1$ (solid), $1: 2$ and $2: 1$ (dashed), and $1: 5$ and $5: 1$ (dotted) lines are shown.

Three statistical metrics were used to evaluate the model performance (Table 3): the fraction of stations with a deviation within a factor of $2\left(F_{2}\right)$ or $5\left(F_{5}\right)$ and the normalized mean bias (NMB). Globally, 57 and $78 \%$ of the stations were associated with deviations within factors of 2 and 5, respectively, with an NMB of $-14 \%$. The model and observations agreed well for East Asia and the Atlantic Ocean, with deviations within a factor of 2 for 84 and $64 \%$ of stations, respectively. The model overestimated $\mathrm{Fe}$ concentrations at some stations over the Atlantic Ocean and the Mediterranean Sea. The model used only one major mode for dust (an initial MMD of $2.5 \mu \mathrm{m}$, and a fixed geometric $\sigma=2.0$ ), which re- 
produces the long-range transport and dust optical thickness over the ocean (Schulz et al., 1998). Without more detailed size bins, we assumed that the $\mathrm{Fe}$ content of dust and the $\mathrm{Fe}$ content of soil in the clay fraction is the same. This assumption is a reasonable approximation for dust transported hundreds of kilometres away from the dust source regions (Formenti et al., 2014), because the lifetime of dust is much longer for the clay fraction (up to 13 days) than for the silt (4 to $40 \mathrm{~h}$ ) and sand (approximately $1 \mathrm{~h}$ ) fractions (Tegen and Fung, 1994). However, the mineralogy and therefore the density of material are not well considered in this simplification. This assumption would lead to an overestimation of the $\mathrm{Fe}$ content of dust near the source regions due to the ignored contribution of $\mathrm{Fe}$ in the silt and sand fractions (which have lower Fe contents than clay) (Formenti et al., 2014). To illustrate this impact, the global distribution of Fe content in dust simulated by assuming that Fe content of emitted dust is equal to that in the clay fraction of soil is shown in Fig. S4. We can see that the Fe content in dust over the Sahara Desert is $4.5-5.5 \%$, which decreases with the distance to the Sahara Desert. According to a measurement at a site with a distance of about $2000 \mathrm{~km}$ to the Sahara Desert, the Fe content in dust is $2.5-2.7 \%$ when the dust is originated from local erosion and $4.3 \%$ when dust is originated from the Sahara Desert (Formenti et al., 2014). In the model, the Fe content is $4.5-5.5 \%$ over the Sahara Desert, which is higher than the measured 2.5-2.7\%, and 4-5\% over the regions distant from the Sahara Desert, close to the measured $4.3 \%$ in dust after a long-range transport from the Sahara Desert (Formenti et al., 2014). In addition, when compiling data in the mineralogy database, Journet et al. (2014) noticed that wet sieving is used to determine soil texture, leading to loss of soluble minerals (e.g. calcite or gypsum) and a possible overestimation of the content of minerals rich in $\mathrm{Fe}$ such as hematite and goethite. This impact might also contribute to an overestimation of Fe content in dust. The overestimation occurs mainly at stations near continents and the downwind of deserts in Fig. 6, indicating that the modelled Fe concentrations over the ocean were not excessively influenced. The model also underestimated Fe concentrations over the Pacific and Southern Oceans, likely due to the uncertainty in dust emissions and to the transport errors in the Southern Hemisphere, as documented previously (Huneeus et al., 2011, Schulz et al., 2012). Dust emissions over regions of the Southern Hemisphere, such as southern South America and southeastern Africa, require additional investigations.

One should note that modelled monthly mean concentrations were compared to daily measurements at some sites (e.g. measured by cruises) due to a lack of detailed date information in measurements. It also caused some discrepancies between model and observations. As pointed out by Mahowald et al. (2009), some cruise measurements were sensitive to episodic dust events. Mahowald et al. (2009) compared the modelled annual mean Fe concentrations to daily measurements, leading to a potential deviation by a factor
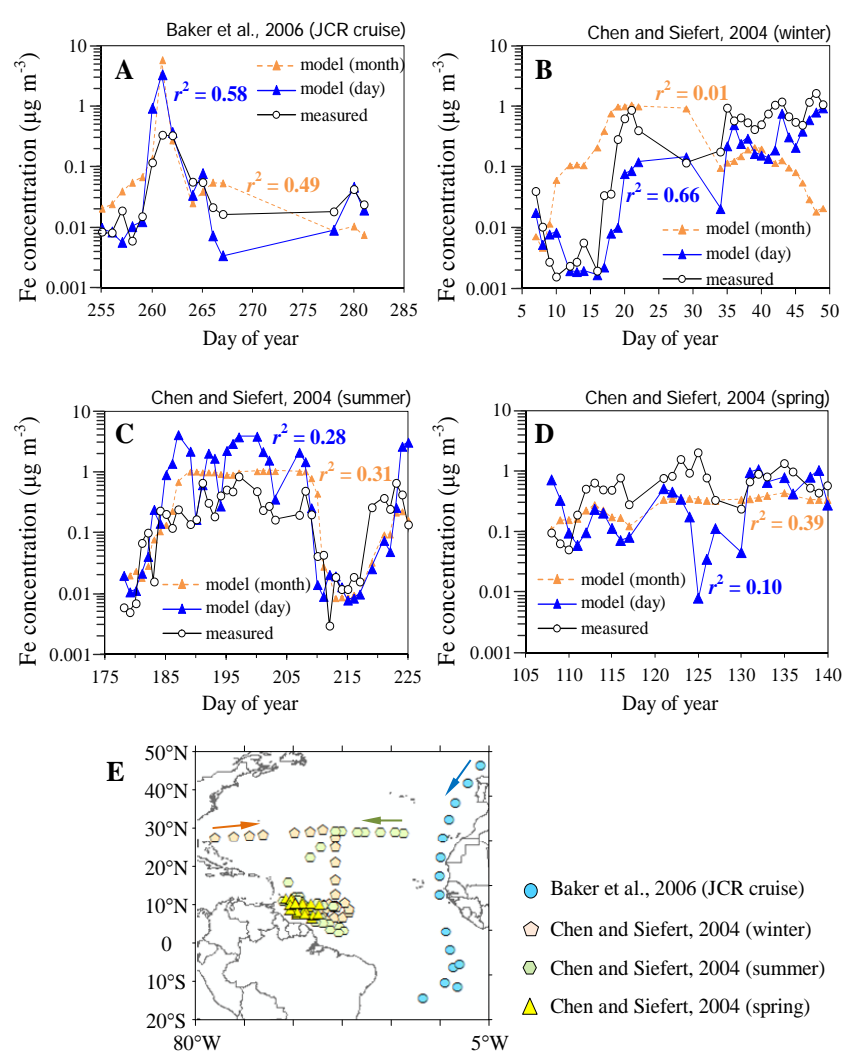

Figure 8. Comparisons of modelled and measured Fe concentrations. The Fe concentrations were derived as monthly (blue triangles) or daily (orange triangles) means from the model. (a) $\mathrm{Fe}$ measured in autumn 2001 (James Clark Ross (JCR) cruise) by Baker et al. (2006). (b) Fe measured in winter 2001 by Chen and Siefert (2004). (c) Fe measured in summer 2001 by Chen and Siefert (2004). (d) Fe measured in spring 2003 by Chen and Siefert (2004). (e) Locations of the cruise measurements (a-d).

up to 10 . We also expected such a bias in this study, even though we were comparing modelled monthly Fe concentrations to all measurements. To address this influence, we compared modelled daily $\mathrm{Fe}$ concentrations to those from some cruise measurements with detailed date information available (Baker et al., 2006; Chen and Siefert, 2004). As illustrated in Fig. 8, particularly in Fig. 8a and b, the variation of daily concentrations could be well captured by the model. These variations were attenuated when using modelled monthly mean $\mathrm{Fe}$ concentrations. This agreement lends support to the estimation of annual mean $\mathrm{Fe}$ concentrations and thus Fe deposition in our study.

\subsection{Fe concentrations over the Atlantic Ocean}

The modelled Fe concentrations attached to aerosols in air near the Atlantic Ocean were compared against 296 transect cruise measurements for 2003-2008 (Baker et al., 2013) (Fig. 9). The zonal distribution of $\mathrm{Fe}$ concentrations was generally captured by the model $\left(r^{2}=0.50\right)$. However, the 


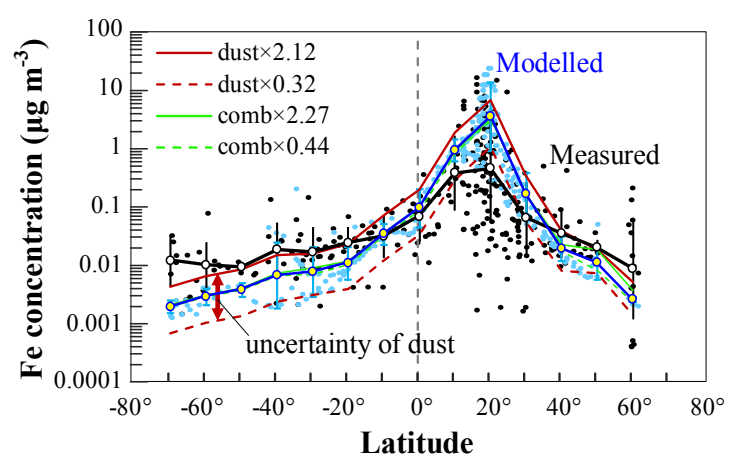

Figure 9. Zonal distribution of modelled (cyan dots) and measured (black dots) Fe concentrations attached to aerosols in surface air over the Atlantic Ocean from $70^{\circ} \mathrm{S}$ to $60^{\circ} \mathrm{N}$. The solid lines with circles show the modelled (blue) and measured (black) Fe concentrations as geometric means in each band with error bars for the geometric standard deviations. As sensitivity tests, Fe concentrations from mineral sources were scaled by factors of 0.32 and 2.12 (solid and dashed red lines) as $90 \%$ uncertainties in dust emissions (Huneeus et al., 2011) and Fe concentrations from combustion sources were scaled by factors of 0.44 and 2.27 (solid and dashed green lines) as $90 \%$ uncertainties in Fe emissions from combustion.

model overestimated the $\mathrm{Fe}$ concentrations in the band between 10 and $20^{\circ} \mathrm{N}$, because $\mathrm{Fe}$ content of the clay fraction was extrapolated to all dust types, leading to an overestimation of Fe concentrations at locations near dust source regions (see the discussion above). In addition, the model underestimated $\mathrm{Fe}$ concentrations by a factor of 2 at stations in the band between 40 and $70^{\circ} \mathrm{S}$, and this model-data misfit could be reduced when the modelled concentrations were scaled by a higher dust emission in a sensitivity test (Fig. 9), confirming the high degree of uncertainties in dust emissions and transport in the Southern Hemisphere.

The seasonality of modelled $\mathrm{Fe}$ concentrations at two long-term monitoring stations on the western margin of the Atlantic Ocean (Bermuda and Barbados) was compared to the observations, collected between 1988 to 1994 during the AEROCE program (Arimoto et al., 1992, 1995, 2003; Huang et al., 1999) and compiled by Sholkovitz et al. (2009). As shown in Fig. 10, the observed seasonal variations of Fe concentrations at these two stations were well represented by the model, with peaks in summer corresponding to dust storms in the Sahara Desert.

\subsection{Role of the combustion sources}

The estimated total emissions and the spatial distributions of Fe from combustion sources differed from those of previous studies (Table 2 and Fig. 3). The contribution of combustion sources to the Fe concentrations attached to aerosols in surface air is shown in Fig. 11. Large contribution of combustion sources $(>80 \%)$ is found in western Europe, southeastern and northeastern China, southern Africa, central South
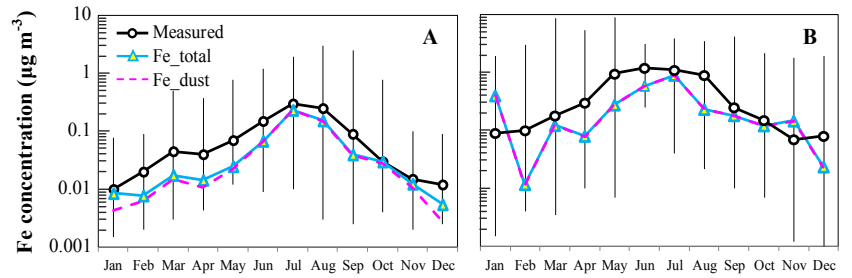

Figure 10. Seasonality of $\mathrm{Fe}$ concentrations attached to aerosols in surface air at Bermuda $\left(32.2^{\circ} \mathrm{N}, 64.5^{\circ} \mathrm{W}\right)$ (a) and Barbados $\left(13.2^{\circ} \mathrm{N}, 59.3^{\circ} \mathrm{W}\right)(\mathbf{b})$ on the western margin of the Atlantic Ocean. Modelled $\mathrm{Fe}$ concentrations are derived from all sources (Fe_total) and from mineral sources only (Fe_dust) as medians of all days of each month of 2005. Measured Fe concentrations are shown as the medians (circles) for 1988-1994 with the ranges between the 10th and 90 th percentiles (error bars).

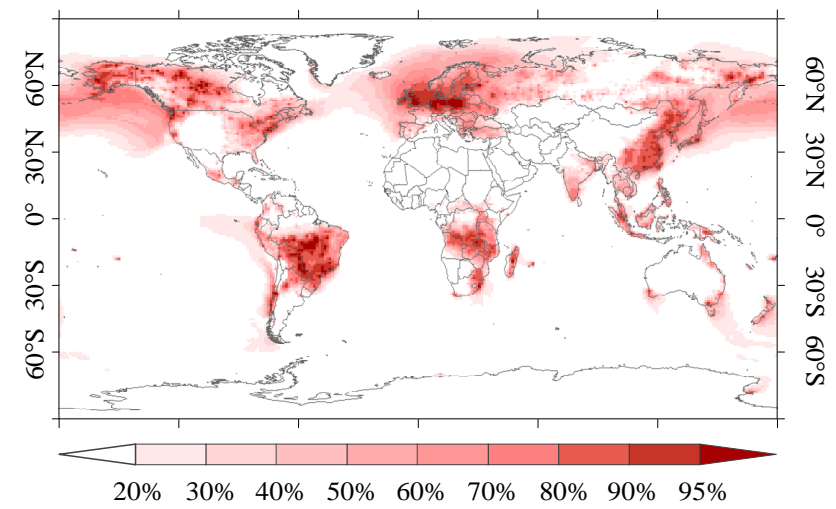

Figure 11. Relative contribution of combustion sources to the modelled Fe concentrations attached to aerosols in surface air.

America and eastern and northern North America, in agreement with the spatial distribution of combustion emissions.

To evaluate our estimation of the combustion sources of $\mathrm{Fe}$, we divided all stations used in Sect. 4.2 into four groups based on the contribution to $\mathrm{Fe}$ concentrations by combustion sources. We plotted the modelled Fe concentrations with or without combustion sources against the observations (Fig. 12). The model can capture the observed Fe concentrations at 53 stations with combustion contributions larger than $50 \%$ well, with an average deviation of a factor of 1.5 . The spatial pattern of Fe concentrations at these 53 stations is also well captured $\left(r^{2}=0.73\right)$, lending good support to our new estimation of $\mathrm{Fe}$ emissions from combustion sources. The scatter for stations with a smaller combustion contribution indicates a higher uncertainty in mineral sources of $\mathrm{Fe}$ than combustion sources.

Due to too heavy computational load, we modelled the Fe concentrations from combustion in a typical year using the average Fe emissions during 1990-2007, and compared them with measurements during 1990-2007 by scaling the modelled $\mathrm{Fe}$ concentrations from combustion to a specific year with the temporal change of emissions at each site (Sect. 2.7). 


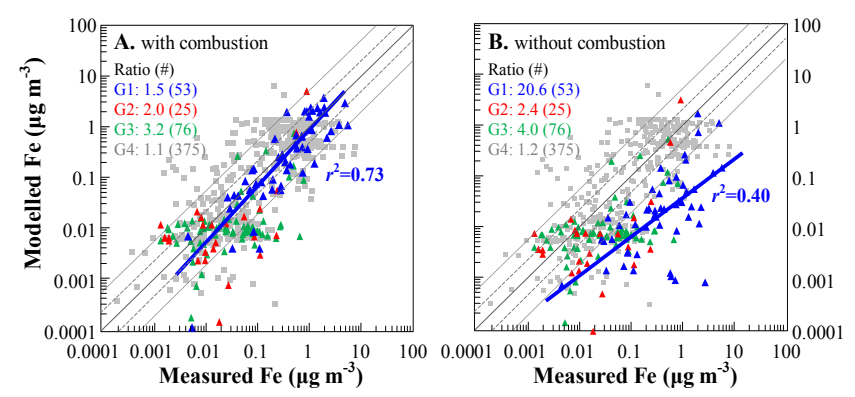

Figure 12. Plots of modelled and measured Fe concentrations attached to aerosols in surface air with (a) or without (b) combustion sources. All stations were divided into four groups based on the contribution of combustion sources: G1, contribution $\geq 50 \%$ (blue triangles); G2, $30 \% \leq$ contribution $<50 \%$ (red triangles); G3: $15 \% \leq$ contribution $<30 \%$ (green triangles); G4, contribution $<15 \%$ (grey squares). The ratios between measured and modelled concentrations as geometric means are listed with the number of stations in parentheses for each group. The fitted curves for the G1 stations are shown as blue lines with coefficients of determination $\left(r^{2}\right)$.

To investigate the influence of this scaling process, we compared the modelled Fe concentrations without scaling among the four groups of sites (see results in Fig. S5). As a result, without this scaling, there is very minor change in the comparison between the modelled and observed Fe concentrations with $r^{2}$ change from 0.73 to 0.72 . This indicates that the variation of Fe concentrations among the measuring sites is dominated by the spatial variation of Fe concentrations.

\subsection{Effect of the new mineralogical database}

Figure 13 shows the difference in modelled Fe concentrations using the new mineralogical data (Journet et al., 2014) relative to that using a constant Fe content in dust $(3.5 \%)$, as widely adopted (Luo et al., 2008; Ito, 2013). The new mineralogical data increased the global total Fe emission from mineral sources from 38.5 to $41.0 \mathrm{Tg} \mathrm{yr}^{-1}$, with a relative difference ranging from -60 to $+30 \%$ regionally (Fig. 5). Iron emissions were lower over the Takla-Makan and Gobi deserts (Fig. 5), leading to lower Fe concentrations over East Asia and the downwind regions over the northern Pacific Ocean. In contrast, $\mathrm{Fe}$ emissions were higher over the Sahara Desert and the deserts in the Middle East, southern Africa and central Australia (Fig. 5), leading to higher Fe concentrations over the Atlantic and Southern oceans.

The effect of the new mineralogical database on the model-observation comparison at all stations used in Sect. 4.2 is shown in Fig. 14. All stations were divided into four groups based on the relative differences in Fig. 13. The influence was not very significant. There are 49 stations with a relative difference larger than $30 \%$, where the model bias was reduced from 40 to $20 \%$. The new mineralogical data also led to modest improvements in the comparison of mod-

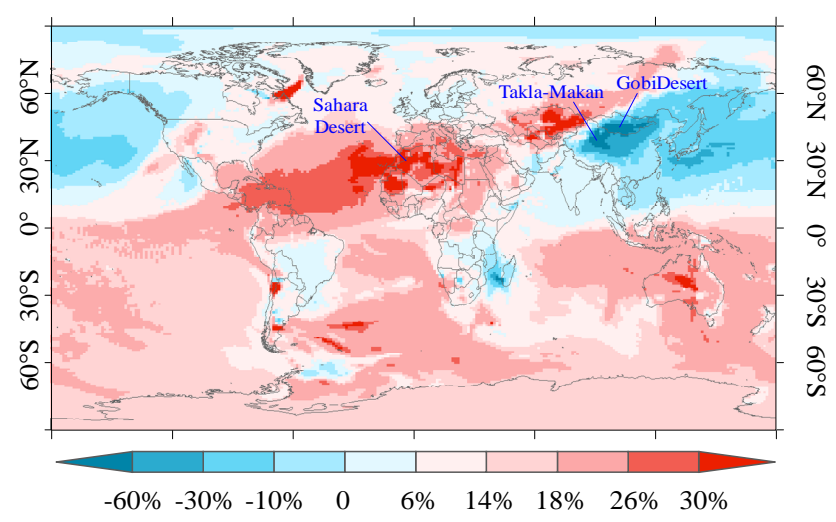

Figure 13. Relative differences in simulated Fe concentrations attached to aerosols in surface air when using the new mineralogical data and prescribing a constant $\mathrm{Fe}$ content in dust (3.5\%). A positive difference indicates a higher Fe concentration when using the new mineralogical data.

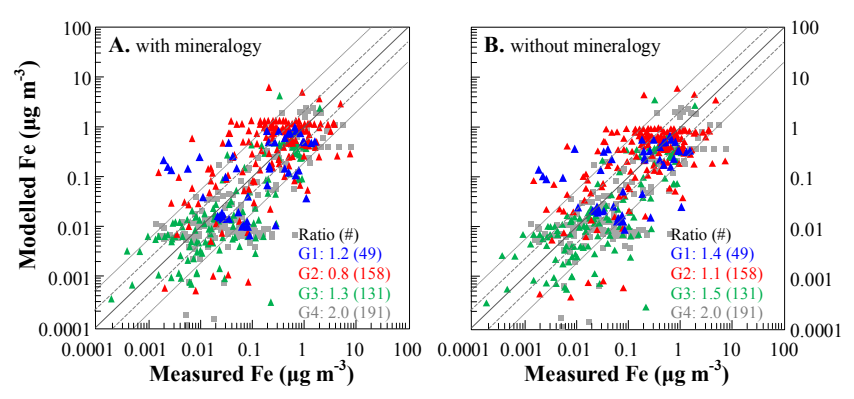

Figure 14. Plots of modelled and measured Fe concentrations attached to aerosols in surface air. The Fe content of dust was calculated from the new mineralogical data (a) or prescribed as $3.5 \%$ (b). All stations were divided into four groups based on the relative differences between (a) and (b): G1, difference $\geq 30 \%$ (blue triangles); G2, $20 \% \leq$ difference $<30 \%$ (red triangles); G3: $10 \% \leq$ difference $<20 \%$ (green triangles); G4, difference $<10 \%$ (grey squares). The ratios between measured and modelled concentrations as geometric means are listed with the number of stations in parentheses for each group.

elled and observed Fe concentrations in surface air over the Atlantic Ocean at all stations used in Fig. 9 of Sect. 4.3, with a slight improvement of the underestimation at latitudes between 40 and $70^{\circ} \mathrm{S}$ (Fig. S6). The limited improvement obtained using the state-of-the-art mineralogical database implied that other factors, such as the dust emission uncertainties and the transport errors, influenced the estimation of $\mathrm{Fe}$ from mineral sources. Further studies are needed to constrain the dust emissions in the Southern Hemisphere in the model (Tagliabue et al., 2009; Schulz et al., 2012). The new mineralogical data provided information on the chemical form of the Fe in dust (Journet et al., 2014), which will help the modelling of Fe solubility. 


\subsection{Size distributions of Fe-containing particles}

The particle size of Fe-containing particles is an important factor controlling the lifetime and solubility of $\mathrm{Fe}$ (Baker and Jickells, 2006; Mahowald et al., 2009). In LMDZ-INCA, the size distribution of Fe-containing particles was treated as a log-normal distribution with a varied MMD and a fixed geometric $\sigma$. Figure 15 shows the spatial distribution of modelled wet MMD of Fe-containing particles in surface air from combustion and mineral sources. The global average wet MMD of Fe-containing particles is $2.6 \mu \mathrm{m}$. The figure also illustrates that the Fe was mainly attached to coarse particles $(>5.0 \mu \mathrm{m})$ in regions dominated by combustion sources, such as in East Asia, South Asia, Europe, eastern and northern North America, South America and southern Africa. By contrast, the wet MMD of Fe-containing particles is 2.2-2.4 $\mu \mathrm{m}$ over the deserts dominated by mineral sources, such as in northern Africa, western Asia and southeastern North America, slightly smaller than the initialized wet MMD for dust.

According to Schulz et al. (2007), after the particles containing $\mathrm{Fe}$ are emitted into the atmosphere, there are three major processes that change the size distribution in the model. First, formation of sulfate increases the aerosol mass in the accumulation mode and, since the particle number is kept constant, the aerosol diameter increases for Fe in $\mathrm{PM}_{1}$. Second, removing processes such as sedimentation removes the larger particles more efficiently, shifting the mode diameter to a smaller one for $\mathrm{Fe}$ in $\mathrm{PM}_{1}, \mathrm{PM}_{1-10}$ and $\mathrm{PM}_{>} 10$. Finally, the hygroscopic growth creates instantaneous changes in the size of particles as a function of ambient relative humidity (Schulz et al., 2007), and the uptake of water on aerosols increases the size, while the loss of water on aerosols decreases the size. Therefore, the change of the size of $\mathrm{Fe}$ is dependent on the relative importance of the mechanisms increasing/decreasing the size. For example, the size of $\mathrm{Fe}$ in $\mathrm{PM}_{1}$ emitted from coal combustion increased from 0.3 to $>2 \mu \mathrm{m}$ after being transported away from the source regions, because the hygroscopic growth by uptake of water on aerosol particles is more important. In contrast, the size of $\mathrm{Fe}$ in $\mathrm{PM}_{>10}$ emitted from coal combustion in East Asia decreases over the southern Pacific Ocean, because sedimentation is the dominating process. The size of $\mathrm{Fe}$ in $\mathrm{PM}_{>} 10$ from coal combustion would decrease from $33 \mu \mathrm{m}$ in the source regions to $<10 \mu \mathrm{m}$ over the oceans.

There are limited measurements of size distributions of Fe-containing particles. Sun et al. (2004) measured the Fe concentrations in $\mathrm{PM}_{2.5}$ and $\mathrm{PM}_{10}$ at three stations in Beijing. The mean $\pm \sigma$ of the $\mathrm{PM}_{2.5} / \mathrm{PM}_{10}$ ratios of $\mathrm{Fe}$ was $28.1 \pm 7.8 \%$, compared to $33.5 \pm 1.6 \%$ in our simulation. Chen and Siefert (2004) measured the Fe concentrations in $\mathrm{PM}_{2.5}$ and total suspended particles (TSP) over the North Atlantic Ocean. The mean $\pm \sigma$ of the $\mathrm{PM}_{2.5}$ / TSP ratios of Fe was $55.2 \pm 16.8 \%$, compared to the $49.9 \pm 0.5 \%$ in our simulation.

\section{Global Fe deposition}

The distribution of annual mean $\mathrm{Fe}$ deposition is shown in Fig. 16. Similar to the distribution of annual mean $\mathrm{Fe}$ concentrations attached to aerosols in surface air (Fig. 6), the spatial distribution of $\mathrm{Fe}$ deposition was dominated by mineral sources. High $\mathrm{Fe}$ deposition rates over the oceans were found over the Arabian Sea and the Indian Ocean (> $\left.100 \mathrm{mg} \mathrm{m}^{-2} \mathrm{yr}^{-1}\right)$, followed by the Atlantic Ocean (10-100 $\mathrm{mg} \mathrm{m}^{-2} \mathrm{yr}^{-1}$ ) and the northern Pacific Ocean (5$30 \mathrm{mg} \mathrm{m}^{-2} \mathrm{yr}^{-1}$ ). Mahowald et al. (2009) pointed out that directly measured $\mathrm{Fe}$ deposition rates are very limited. We compared the modelled Fe deposition with in situ measurements compiled by Mahowald et al. (2009). The spatial pattern of measured $\mathrm{Fe}$ deposition can be generally represented by the model $\left(r^{2}=0.88\right)$ (Fig. S7). The limited data, however, prevented us from evaluating the modelled deposition rates globally.

\section{Global atmospheric Fe budget}

The atmospheric Fe budgets from different emission sources are summarized in Table 4. The atmospheric lifetime of $\mathrm{Fe}$ is highly dependent on the particle size, the emission source and the meteorological conditions. For example, the atmospheric lifetime changes from 0.08 days for $\mathrm{Fe}$ of $\mathrm{PM}_{>}$ from biomass burning to 4.1 days of $\mathrm{PM}_{1-10}$ and 9.4 days of $\mathrm{PM}_{1}$, because larger particles can be more efficiently removed by sedimentation than smaller ones. The atmospheric lifetime also differs for Fe from different emission sources. For example, the atmospheric lifetime of $\mathrm{Fe}$ of $\mathrm{PM}_{1}$ emitted from biomass burning is twice that for $\mathrm{Fe}$ of $\mathrm{PM}_{1}$ emitted from coal combustion. For the wet deposition only, the atmospheric lifetime of $\mathrm{Fe}$ of $\mathrm{PM}_{1}$ emitted from biomass burning was 15.2 days, compared to 9.4 days for $\mathrm{Fe}$ of $\mathrm{PM}_{1}$ emitted from coal combustion. Less precipitation and scavenging over the drier African savanna, the major region of $\mathrm{Fe}$ emissions from biomass burning, can explain this difference. The atmospheric burden of $\mathrm{Fe}$ and the atmospheric deposition of $\mathrm{Fe}$ over the oceans are both dominated by mineral sources, due to a larger total emission source.

We estimate that the annual deposition of total $\mathrm{Fe}$ over global oceans is $8.4 \mathrm{Tg} \mathrm{yr}^{-1}$ over the studied period (19902007). Among the total Fe deposition over the oceans, 93.1, $5.4,1.4$ and $0.13 \%$ was originated from dust $\left(7.82 \mathrm{Tg} \mathrm{yr}^{-1}\right)$, coal combustion $\left(0.455 \mathrm{Tg} \mathrm{yr}^{-1}\right)$, biomass $\left(0.122 \mathrm{Tg} \mathrm{yr}^{-1}\right)$ and oil combustion $\left(0.011 \mathrm{Tg} \mathrm{yr}^{-1}\right)$. In a recent global study modelling the Fe solubility, Ito (2015) estimated a larger deposition of $\mathrm{Fe}$ from mineral dust $\left(13 \mathrm{Tg} \mathrm{yr}^{-1}\right)$, biomass burning $\left(0.14 \mathrm{Tg} \mathrm{yr}^{-1}\right)$ and oil combustion $\left(0.02 \mathrm{Tg} \mathrm{yr}^{-1}\right)$, but a lower deposition of $\mathrm{Fe}$ from coal combustion $\left(0.16 \mathrm{Tg} \mathrm{yr}^{-1}\right)$, mainly due to the difference in the estimation for the sources (Table 2). 

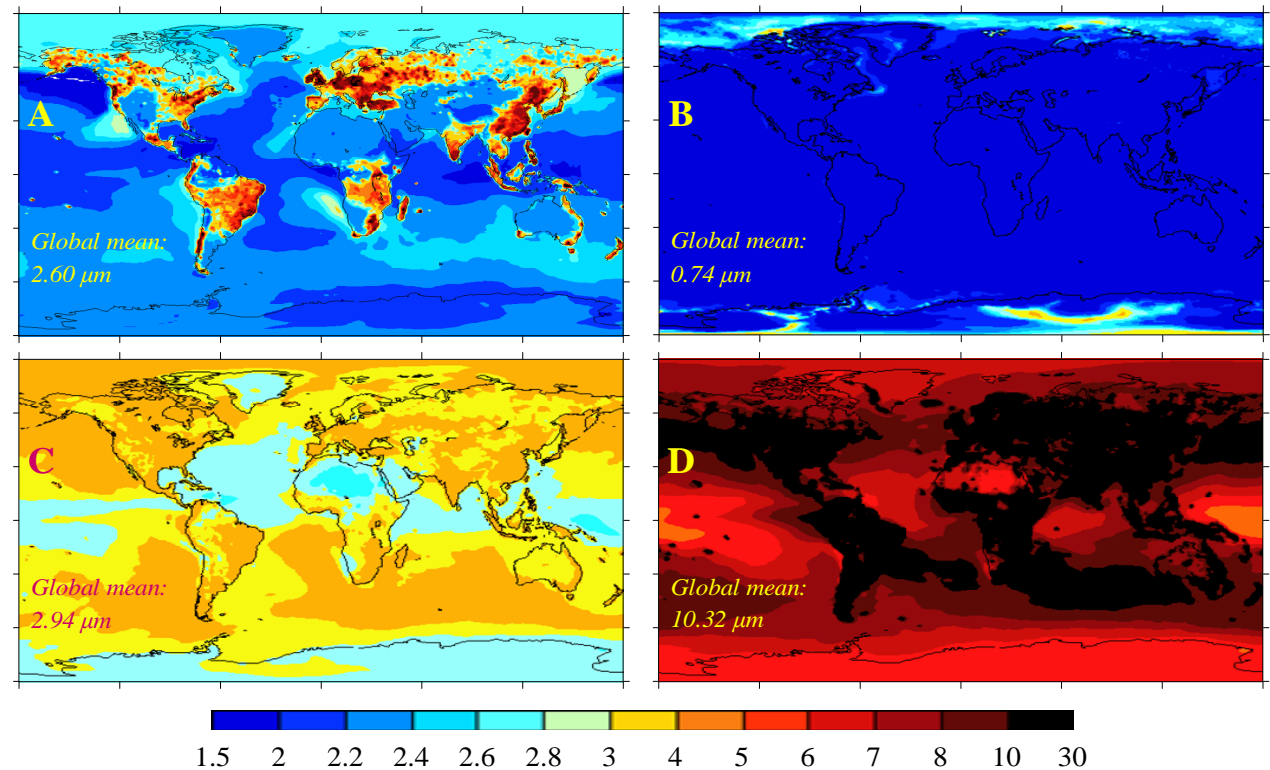

Figure 15. Spatial distributions of the wet mass median diameter $(\mu \mathrm{m})$ of Fe-containing particles in surface air. (a) Fe from all combustion and mineral sources. (b-d) Fe from coal combustion in $\mathrm{PM}_{1}(\mathbf{b}), \mathrm{PM}_{1-10}$ (c) and $\mathrm{PM}_{>10}$ (d). The global mean is provided in each panel.

Table 4. Global Fe budgets from various sources and from different particle size classes. The total deposition of Fe was calculated over land and oceans separately, and was also calculated for the dry deposition (DRY), wet deposition (WET), and sedimentation (SED), respectively.

\begin{tabular}{lrrrrrrrrr}
\hline & $\begin{array}{r}\text { Source } \\
\left(\mathrm{Tg} \mathrm{yr}^{-1}\right)\end{array}$ & $\begin{array}{r}\text { Burden } \\
(\mathrm{Gg})\end{array}$ & $\begin{array}{r}\text { Lifetime } \\
(\text { days })\end{array}$ & \multicolumn{2}{c}{$\begin{array}{c}\text { Deposition } \\
\left(\mathrm{Tg} \mathrm{yr}^{-1}\right)\end{array}$} & \multicolumn{3}{c}{$\begin{array}{c}\text { Deposition } \\
\left(\mathrm{Tg} \mathrm{yr}^{-1}\right)\end{array}$} \\
\cline { 2 - 9 } & & & & $\begin{array}{r}\text { Over } \\
\text { land }\end{array}$ & $\begin{array}{r}\text { Over } \\
\text { ocean }\end{array}$ & DRY & WET & SED \\
\hline Coal & & & & & & & & \\
\hline PM $_{1}$ & 0.018 & 0.262 & 5.28 & 0.013 & 0.005 & 0.008 & 0.010 & 0.0002 \\
PM $_{1-10}$ & 1.025 & 6.437 & 2.30 & 0.807 & 0.215 & 0.310 & 0.331 & 0.381 \\
PM $_{>} 10$ & 3.167 & 0.431 & 0.05 & 2.905 & 0.235 & 0.142 & 0.026 & 2.971 \\
Total & 4.210 & 7.131 & 0.26 & 3.724 & 0.455 & 0.460 & 0.367 & 3.352 \\
\hline Petroleum & & & & & & & & \\
\hline PM $_{1}$ & 0.020 & 0.289 & 5.20 & 0.010 & 0.010 & 0.007 & 0.013 & 0.0002 \\
PM $_{1-10}$ & 0.002 & 0.014 & 2.22 & 0.001 & 0.001 & 0.001 & 0.001 & 0.001 \\
Total & 0.022 & 0.303 & 4.79 & 0.011 & 0.011 & 0.008 & 0.014 & 0.001 \\
\hline Biomass & & & & & & & & \\
\hline PM $_{1}$ & 0.018 & 0.466 & 9.40 & 0.012 & 0.006 & 0.006 & 0.010 & 0.0003 \\
PM $_{1-10}$ & 0.482 & 5.303 & 4.12 & 0.367 & 0.103 & 0.130 & 0.184 & 0.154 \\
PM $_{>} 10$ & 0.375 & 0.083 & 0.08 & 0.353 & 0.013 & 0.017 & 0.004 & 0.344 \\
Total & 0.875 & 5.852 & 1.27 & 0.731 & 0.122 & 0.154 & 0.199 & 0.498 \\
\hline Dust & 41.0 & 442 & 3.95 & 33.0 & 7.82 & 15.3 & 15.1 & 10.4 \\
\hline
\end{tabular}

\section{Influence of different $\mathrm{Fe}$ solubilities from different sources}

The form and chemical properties of $\mathrm{Fe}$ vary greatly among different sources, which determine the solubility and bioavailability of Fe (Boyd et al., 2000; Moore et al., 2004). Measured Fe solubility is $77-81 \%$ in oil fly ash (Schroth et al., 2009) against only 20-25\% in coal fly ash (Chen et al., 2012), and approximately $18 \%$ in biomass fly ash (Bowie et al., 2009). Note that solubility of Fe from any combus- 


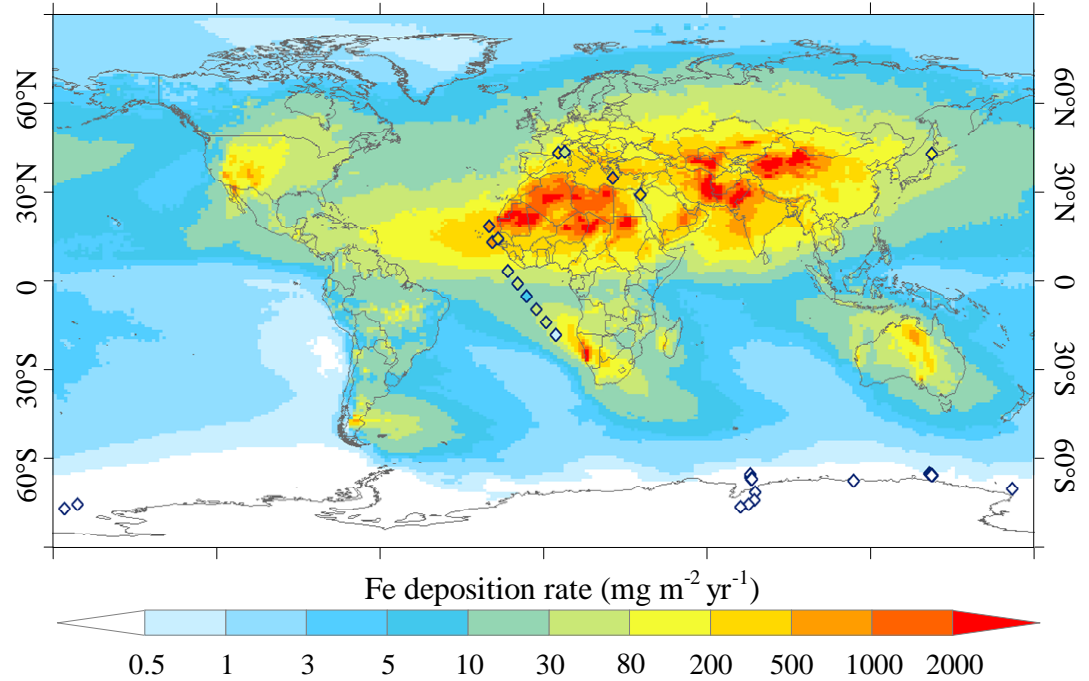

Figure 16. Global distribution of modelled annual mean Fe deposition rates. The observed Fe deposition rates from in situ measurements compiled by Mahowald et al. (2009) are shown as diamonds of the same colour as the scale.

tion source is much larger than the $0.44 \%$ in dust from the Sahara Desert (Sedwick et al., 2007). One of the key findings of this study is the identification of $\mathrm{Fe}$ emissions from combustion sources. As shown in Fig. 17, the contribution by the combustion of petroleum and coal to the total Fe deposition exceeds 1 and $3 \%$, respectively, over many oceans such as the northern Atlantic and northern Pacific Oceans. Considering their relatively high Fe solubility, the contribution of combustion sources to soluble Fe supply for these oceanic ecosystems could be amplified by 1-2 orders of magnitude. The additional input of soluble Fe from combustion sources may lead to profound biological effects over the northern Pacific, northern Atlantic and Southern Oceans, where $\mathrm{Fe}$ is identified as the primary limiting nutrient for the growth of phytoplankton (Moore et al., 2013). As a preliminary study, we calculated the deposition of soluble Fe from different sources using constant $\mathrm{Fe}$ solubilities $(0.44 \%$ for dust, $22.5 \%$ for coal fly ash, $79 \%$ for oil fly ash and $18 \%$ for biomass fly ash). Figure 18 shows the relative contribution of combustion-related $\mathrm{Fe}$ emissions to total soluble $\mathrm{Fe}$ deposition over global oceans. With a larger Fe solubility, the effective contribution of combustion sources is larger despite their smaller mass contribution than dust over most oceanic regions. As illustrated in Fig. 19, consideration of Fe from combustion sources, with assumed constant Fe solubilities for different sources, can largely improve the modelled soluble Fe concentrations when comparing against observations at 176 sites over the Atlantic and Pacific oceans (Baker et al., 2007; Sedwick et al., 2007; Buck et al., 2006, 2010). Further improvement of the modelled soluble Fe concentrations requires an explicit modelling of the atmospheric processing of Fe emitted from mineral dust and combustion sources, which is beyond the target of the present study. The produced maps of Fe deposition from different fuel types and from different sizes will help simulate the chemical processing of $\mathrm{Fe}$ in the atmosphere.

According to our estimation, combustion-related sources contribute $79 \%$ to the total deposition of soluble $\mathrm{Fe}$ over the oceans. Note that this estimate is dependent on the Fe solubility prescribed for different sources, and the influences by chemical, physical or photochemical factors have not been considered in our estimate. As a result, the predicted contribution by combustion-related sources to soluble Fe deposition over global oceans is a factor of 5 higher than the $15 \%$ estimated in a recent study (Ito, 2015). In that work, Ito has explicitly modelled the dissolution of Fe in fly ash due to photochemical reactions with inorganic and organic acids in solution. It results in a global average Fe solubility of $2 \%$ for dust, $21 \%$ for biomass fly ash, $8 \%$ for coal fly ash, and $65 \%$ for oil fly ash, which differs from the measurements used in our estimate (Sedwick et al., 2007; Bowie et al., 2009; Schroth et al., 2009; Chen et al., 2012). However, as also pointed out by Ito (2015), there is a large uncertainty in the modelled Fe solubility due to large uncertainties associated with prescribed $\mathrm{Fe}$ solubility at emission, which is dependent on the condition of combustion sources (Ito, 2015). More measurements of $\mathrm{Fe}$ solubility at various sources and open oceans should be conducted to simulate and constrain the $\mathrm{Fe}$ solubility in the future work.

In addition, the study by Lin et al. (2015) predicted that 87 and $41 \%$ of the deposition of soluble Fe over the northwestern Pacific Ocean could be attributed to combustion-related sources when prescribing a solubility of 40 and $4 \%$ for $\mathrm{Fe}$ in fly ash, respectively. Their upper estimate agrees well with our prediction that combustion-related sources would 


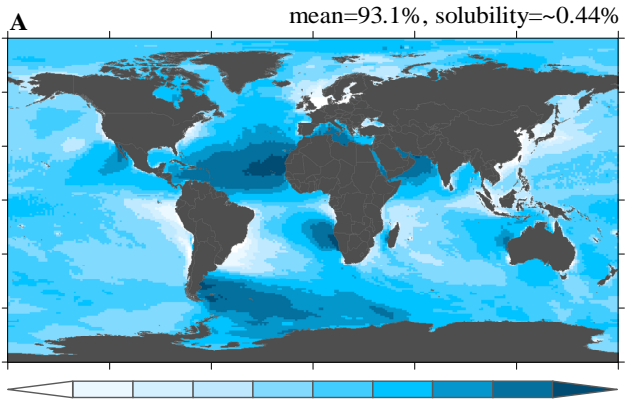

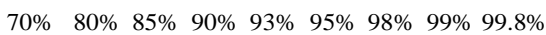

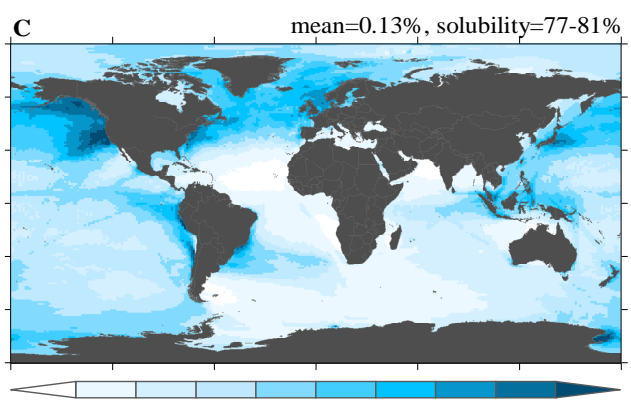

$\begin{array}{lllllllll}0.02 \% & 0.1 \% & 0.2 \% & 0.3 \% & 0.5 \% & 0.7 \% & 1 \% & 1.5 \% & 2 \%\end{array}$

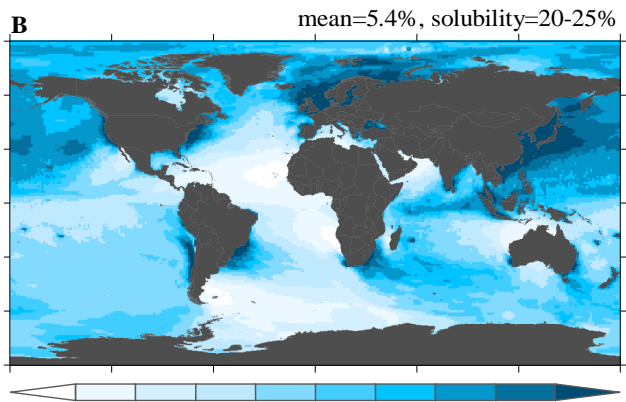

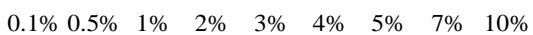

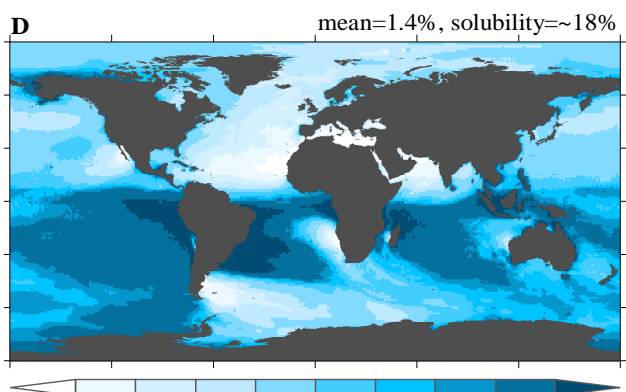

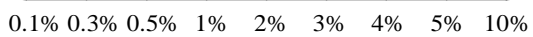

Figure 17. Relative contributions of atmospheric Fe deposition over oceans by mineral sources (a) and combustion of coal (b), oil (c) and biomass (d). The average contribution over the oceans and the measured Fe solubility are provided in the panel descriptions. Colour scales differ on each plot.

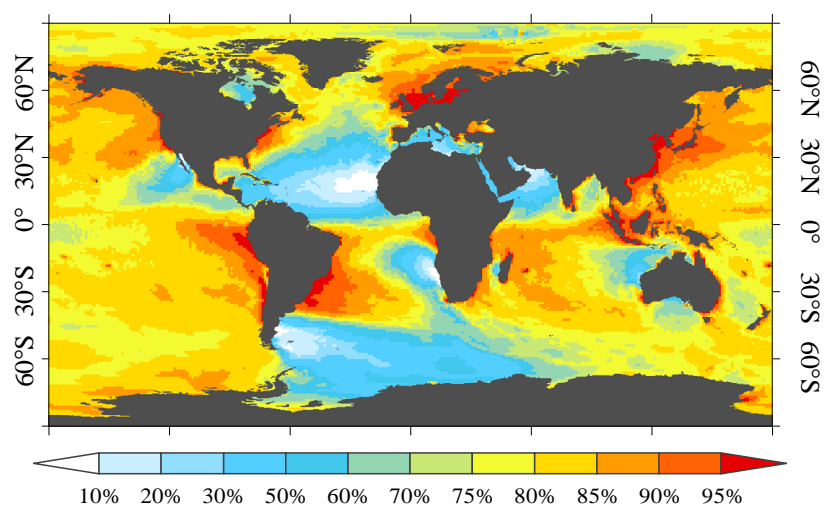

Figure 18. Relative contribution of combustion-related emissions to atmospheric soluble Fe deposition over oceans. Constant Fe solubilities $(0.44 \%$ for dust, $22.5 \%$ for coal fly ash, $79 \%$ for oil fly ash and $18 \%$ for biomass fly ash) were applied to calculate the deposition of soluble Fe from the deposition of total Fe.

contribute $80-95 \%$ to soluble Fe deposition in this region (Fig. 18).

\section{Summary and conclusion}

We developed a new emission inventory of Fe from combustion sources using $\mathrm{Fe}$ contents of fuel and $\mathrm{Fe}$ partitioning during combustion, and estimated the emissions of Fe from mineral sources based on a new soil mineralogical database. We calculated the global total $\mathrm{Fe}$ emissions of 0.046, 1.4, and $3.8 \mathrm{Tg} \mathrm{yr}^{-1}$ in $\mathrm{PM}_{1}, \mathrm{PM}_{1-10}$ and $\mathrm{PM}_{>10}$ from combustion sources, respectively. Although the total Fe emissions are similar, the size distributions and the source profiles differ from those in previous studies, which substantially influenced the Fe solubility in aerosols.

We evaluated the estimated new emissions of Fe from combustion and mineral sources. We introduced the estimated Fe emissions in a global transport model running at a resolution of $0.94^{\circ}$ latitude by $1.28^{\circ}$ longitude. The modelled $\mathrm{Fe}$ concentrations attached to aerosols in surface air were compared with 825 measurements worldwide. The measured Fe concentrations were generally predicted by the model, including the spatial distributions of $\mathrm{Fe}$ concentrations in each region, the zonal distributions of $\mathrm{Fe}$ concentrations over the Atlantic Ocean, and the seasonality of Fe concentrations on the western margin of the Atlantic Ocean. Importantly, agreement was good at stations where the $\mathrm{Fe}$ concentrations were dominated by combustion sources, supporting our new estimations of Fe emissions from combustion sources. The new mineralogical data produced modest improvements but provided useful information on the chemical form of Fe. An underestimation of $\mathrm{Fe}$ concentrations over the oceans in the Southern Hemisphere, however, may confirm the high uncertainty in dust emissions, which deserves further study. 


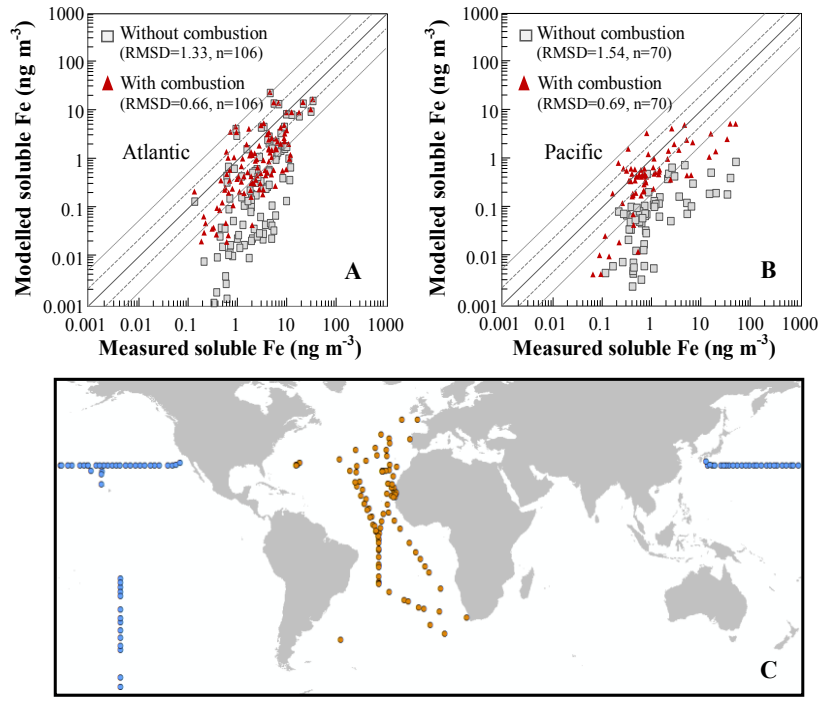

Figure 19. Comparison of modelled and observed soluble Fe concentrations over the Atlantic (a) and Pacific (b) oceans. Model simulations were run for 2004 and 2005 with the Fe emissions from mineral dust, but without (grey squares) or with (red triangles) the emissions from combustion. Fixed Fe solubilities were applied for Fe from mineral dust $(0.44 \%)$ and combustion of coal $(22.5 \%)$, oil $(79 \%)$ and biomass $(18 \%)$. The measured daily soluble $\mathrm{Fe}$ concentrations in 2004 and 2005 were compiled from the literature (Baker et al., 2007; Sedwick et al., 2007; Buck et al., 2006, 2010). The modelled and observed soluble Fe concentrations were compared on the same days. To evaluate the model performance, the root mean square deviations (RMSD) are computed for $\log _{10^{-}}$ transformed concentrations. The $1: 1$ (solid), $1: 2$ and $2: 1$ (dashed), and $1: 5$ and $5: 1$ (dotted) lines are shown. Locations of the measurement sites are shown in (c).

We estimated a total $\mathrm{Fe}$ deposition sink of $8.4 \mathrm{Tg} \mathrm{yr}^{-1}$ over global oceans, $7 \%$ of which originated from combustion sources. The modelled Fe deposition rates were confirmed by a limited number of in situ measurements. Fe deposition rates over most oceanic regions, however, have not been widely measured. The combustion of coal, petroleum and biomass, all with a much higher Fe solubility than that in dust, contributed considerably to the deposition of Fe over the northern Atlantic and northern Pacific Oceans. We speculate that this large amount of additional input of soluble Fe may have had an impact on the oceanic carbon cycle and the global climate.

\section{The Supplement related to this article is available online at doi:10.5194/acp-15-6247-2015-supplement.}

Acknowledgements. The authors thank Ether/ECCAD for distribution of emission data used in this study. R. Wang was supported by the "FABIO" project, a Marie Curie International Incoming Fellowship from the European Commission. This work was also supported by the European Research Council Synergy Grant IMBALANCE-P (ERC-SyG-2013-610028). The simulations in this work were performed using DSM-CCRT resources under the GENCI (Grand Equipement National de Calcul Intensif) computer time allocation (grant 2014-t2014012201).

Edited by: K. Tsigaridis

\section{References}

Arimoto, R., Duce, R. A., Savoie, D. L., and Prospero, J. M.: Traceelements in aerosol-particles from Bermuda and Barbados - concentrations, sources and relationships to aerosol sulfate, J. Atmos. Chem., 14, 439-457, doi:10.1007/Bf00115250, 1992.

Arimoto, R., Duce, R. A., Ray, B. J., Ellis, W. G., Cullen, J. D., and Merrill, J. T.: Trace elements in the atmosphere over the North-Atlantic, J. Geophys. Res.-Atmos., 100, 1199-1213, doi:10.1029/94jd02618, 1995.

Arimoto, R., Duce, R. A., Ray, B. J., and Tomza, U.: Dry deposition of trace elements to the western North Atlantic, Global Biogeochem. Cy., 17, 1010, doi:10.1029/2001gb001406, 2003.

Baker, A. R. and Jickells, T. D.: Mineral particle size as a control on aerosol iron solubility, Geophys. Res. Lett., 33, L17608, doi:10.1029/2006gl026557, 2006.

Baker, A. R., Jickells, T. D., Witt, M., and Linge, K. L.: Trends in the solubility of iron, aluminium, manganese and phosphorus in aerosol collected over the Atlantic Ocean, Mar. Chem., 98, 4358, doi:10.1016/j.marchem.2005.06.004, 2006.

Baker, A. R., Weston, K., Kelly, S. D., Voss, M., Streu, P., and Cape, J. N.: Dry and wet deposition of nutrients from the tropical Atlantic atmosphere: Links to primary productivity and nitrogen fixation, Deep-Sea Res. Pt. I, 54, 1704-1720, 2007.

Baker, A. R., Adams, C., Bell, T. G., Jickells, T. D., and Ganzeveld, L.: Estimation of atmospheric nutrient inputs to the Atlantic Ocean from $50^{\circ} \mathrm{N}$ to $50^{\circ} \mathrm{S}$ based on large-scale field sampling: iron and other dust-associated elements, Global Biogeochem. Cy., 27, 755-767, doi:10.1002/Gbc.20062, 2013.

Balkanski, Y.: L'Influence des Aérosols sur le Climat, Thèse d'Habilitation à Diriger des Recherches, Université de Versailles Saint-Quentin, Saint-Quentin-en-Yvelines, 2011.

Balkanski, Y., Schulz, M., Claquin, T., Moulin, C., and Ginoux, P.: Global emissions of mineral aerosol: formulation and validation using satellite imagery, in: Emissions of Atmospheric Trace Compounds, edited by: Granier, C., Artaxo, P., and Reeves, C., Advances in Global Change Research, Springer, Dordrecht, the Netherlands, 239-267, 2004.

Balkanski, Y., Schulz, M., Claquin, T., and Guibert, S.: Reevaluation of Mineral aerosol radiative forcings suggests a better agreement with satellite and AERONET data, Atmos. Chem. Phys., 7, 81-95, doi:10.5194/acp-7-81-2007, 2007.

Balkanski, Y., Myhre, G., Gauss, M., Rädel, G., Highwood, E. J., and Shine, K. P.: Direct radiative effect of aerosols emitted by transport: from road, shipping and aviation, Atmos. Chem. Phys., 10, 4477-4489, doi:10.5194/acp-10-4477-2010, 2010. 
Bertine, K. K. and Goldberg, E. D.: Fossil fuel combustion and the major sedimentary cycle, Science, 173, 233-235, doi:10.1126/science.173.3993.233, 1971.

Bettinelli, M., Spezia, S., Baroni, U., and Bizzarri, G.: Determination of trace-elements in fuel oils by inductively-coupled plasma-mass spectrometry after acid mineralization of the sample in a microwave-oven, J. Anal. Atom. Spectrom., 10, 555-560, doi:10.1039/Ja9951000555, 1995.

Bond, T. C., Streets, D. G., Yarber, K. F., Nelson, S. M., Woo, J. H., and Klimont, Z.: A technology-based global inventory of black and organic carbon emissions from combustion, J. Geophys. Res.-Atmos., 109, D14203, doi:10.1029/2003jd003697, 2004.

Bond, T. C., Bhardwaj, E., Dong, R., Jogani, R., Jung, S. K., Roden, C., Streets, D. G., and Trautmann, N. M.: Historical emissions of black and organic carbon aerosol from energy-related combustion, 1850-2000, Global Biogeochem. Cy., 21, GB2018, doi:10.1029/2006gb002840, 2007.

Bowie, A. R., Lannuzel, D., Remenyi, T. A., Wagener, T., Lam, P. J., Boyd, P. W., Guieu, C., Townsend, A. T., and Trull, T. W.: Biogeochemical iron budgets of the Southern Ocean south of Australia: decoupling of iron and nutrient cycles in the subantarctic zone by the summer-time supply, Global Biogeochem. Cy., 23, GB4034, doi:10.1029/2009gb003500, 2009.

Boyd, P. W., Watson, A. J., Law, C. S., Abraham, E. R., Trull, T., Murdoch, R., Bakker, D. C. E., Bowie, A. R., Buesseler, K. O., Chang, H., Charette, M., Croot, P., Downing, K., Frew, R., Gall, M., Hadfield, M., Hall, J., Harvey, M., Jameson, G., LaRoche, J., Liddicoat, M., Ling, R., Maldonado, M. T., McKay, R. M., Nodder, S., Pickmere, S., Pridmore, R., Rintoul, S., Safi, K., Sutton, P., Strzepek, R., Tanneberger, K., Turner, S., Waite, A., and Zeldis, J.: A mesoscale phytoplankton bloom in the polar Southern Ocean stimulated by iron fertilization, Nature, 407, 695-702, doi:10.1038/35037500, 2000.

Buck, C. S., Landing, W. M., Resing, J. A., and Lebon, G. T.: Aerosol iron and aluminum solubility in the northwest Pacific Ocean: Results from the 2002 IOC cruise, Geochem. Geophy. Geosy., 7, Q04M07, doi:10.1029/2005GC000977, 2006.

Buck, C. S., Landing, W. M., Resing, J. A., and Measures, C. I.: The solubility and deposition of aerosol $\mathrm{Fe}$ and other trace elements in the North Atlantic Ocean: Observations from the A16N CLIVAR/ $\mathrm{CO}_{2}$ repeat hydrography section, Mar. Chem., 120, 5770, 2010.

Chalot, M., Blaudez, D., Rogaume, Y., Provent, A. S., and Pascual, C.: Fate of trace elements during the combustion of phytoremediation wood, Environ. Sci. Technol., 46, 13361-13369, doi:10.1021/Es3017478, 2012.

Chaves, E. S., de Loos-Vollebregt, M. T. C., Curtius, A. J., and Vanhaecke, F.: Determination of trace elements in biodiesel and vegetable oil by inductively coupled plasma optical emission spectrometry following alcohol dilution, Spectrochim. Acta B, 66, 733-739, doi:10.1016/j.sab.2011.09.006, 2011.

Chen, H., Laskin, A., Baltrusaitis, J., Gorski, C. A., Scherer, M. M., and Grassian, V. H.: Coal fly ash as a source of iron in atmospheric dust, Environ. Sci. Technol., 46, 2112-2120, doi:10.1021/Es204102f, 2012.

Chen, Y. and Siefert, R. L.: Seasonal and spatial distributions and dry deposition fluxes of atmospheric total and labile iron over the tropical and subtropical North Atlantic Ocean, J. Geophys. Res.-Atmos., 109, D09305, doi:10.1029/2003jd003958, 2004.
Chen, Y. J., Zhi, G. R., Feng, Y. L., Fu, J. M., Feng, J. L., Sheng, G. Y., and Simoneit, B. R. T.: Measurements of emission factors for primary carbonaceous particles from residential rawcoal combustion in China, Geophys. Res. Lett., 33, L20815, doi:10.1029/2006g1026966, 2006.

Chen, Y. L., Wang, R., Shen, H. Z., Li, W., Chen, H., Huang, Y., Zhang, Y. Y., Chen, Y. C., Su, S., Lin, N., Liu, J., Li, B. G., Wang, X. L., Liu, W. X., Coveney, R. M., and Tao, S.: Global mercury emissions from combustion in light of international fuel trading, Environ. Sci. Technol., 48, 1727-1735, doi:10.1021/Es404110f, 2014.

Chuang, P. Y., Duvall, R. M., Shafer, M. M., and Schauer, J. J.: The origin of water soluble particulate iron in the Asian atmospheric outflow, Geophys. Res. Lett., 32, L07813, doi:10.1029/2004g1021946, 2005.

Conway, T. M. and John, S. G.: Quantification of dissolved iron sources to the North Atlantic Ocean, Nature, 511, 212-215, doi:10.1038/Nature13482, 2014.

Duce, R. A. and Tindale, N. W.: Atmospheric transport of iron and its deposition in the ocean, Limnol. Oceanogr., 36, 1715-1726, 1991.

Espinosa, A. J. F., Rodriguez, M. T., de la Rosa, F. J. B., and Sanchez, J. C. J.: A chemical speciation of trace metals for fine urban particles, Atmos. Environ., 36, 773-780, 2002.

Fan, S. M., Moxim, W. J., and Levy, H.: Aeolian input of bioavailable iron to the ocean, Geophys. Res. Lett., 33, L07602, doi:10.1029/2005gl024852, 2006.

Font, O., Cordoba, P., Leiva, C., Romeo, L. M., Bolea, I., Guedea, I., Moreno, N., Querol, X., Fernandez, C., and Diez, L. I.: Fate and abatement of mercury and other trace elements in a coal fluidised bed oxy combustion pilot plant, Fuel, 95, 272-281, doi:10.1016/j.fuel.2011.12.017, 2012.

Formenti, P., Caquineau, S., Desboeufs, K., Klaver, A., Chevaillier, S., Journet, E., and Rajot, J. L.: Mapping the physicochemical properties of mineral dust in western Africa: mineralogical composition, Atmos. Chem. Phys., 14, 10663-10686, doi:10.5194/acp-14-10663-2014, 2014.

Fu, H. B., Lin, J., Shang, G. F., Dong, W. B., Grassian, V. H., Carmichael, G. R., Li, Y., and Chen, J. M.: Solubility of iron from combustion source particles in acidic media linked to iron speciation, Environ. Sci. Technol., 46, 11119-11127, doi:10.1021/Es302558m, 2012.

Fung, I. Y., Meyn, S. K., Tegen, I., Doney, S. C., John, J. G., and Bishop, J. K. B.: Iron supply and demand in the upper ocean, Global Biogeochem. Cy., 14, 281-295, doi:10.1029/1999gb900059, 2000.

Furuya, K., Miyajima, Y., Chiba, T., and Kikuchi, T.: Elemental characterization of particle-size density separated coal fly-ash by spectrophotometry, inductively coupled plasma emission-spectrometry, and scanning electron-microscopy energy dispersive-X-ray analysis, Environ. Sci. Technol., 21, 898903, doi:10.1021/es00163a008, 1987.

Gao, Y., Kaufman, Y. J., Tanre, D., Kolber, D., and Falkowski, P. G.: Seasonal distributions of aeolian iron fluxes to the global ocean, Geophys. Res. Lett., 28, 29-32, doi:10.1029/2000g1011926, 2001.

Gerber, H. E.: Atmospheric Aerosols and Nucleation, in: Lecture Notes Physics, Springer, New York, 237-238, 1988. 
Granier, C., Bessagnet, B., Bond, T., D’Angiola, A., van der Gon, H. D., Frost, G. J., Heil, A., Kaiser, J. W., Kinne, S., Klimont, Z., Kloster, S., Lamarque, J. F., Liousse, C., Masui, T., Meleux, F., Mieville, A., Ohara, T., Raut, J. C., Riahi, K., Schultz, M. G., Smith, S. J., Thompson, A., van Aardenne, J., van der Werf, G. R., and van Vuuren, D. P.: Evolution of anthropogenic and biomass burning emissions of air pollutants at global and regional scales during the 1980-2010 period, Climatic Change, 109, 163-190, doi:10.1007/s10584-011-0154-1, 2011.

Gregg, W. W., Ginoux, P., Schopf, P. S., and Casey, N. W.: Phytoplankton and iron: validation of a global three-dimensional ocean biogeochemical model, Deep-Sea Res. Pt. II, 50, 3143-3169, doi:10.1016/j.dsr2.2003.07.013, 2003.

Grubler, A., Nakicenovic, N., and Victor, D. G.: Dynamics of energy technologies and global change, Energ. Policy, 27, 247-280, doi:10.1016/S0301-4215(98)00067-6, 1999.

Guelle, W., Balkanski, Y. J., Schulz, M., Marticorena, B., Bergametti, G., Moulin, C., Arimoto, R., and Perry, K. D.: Modeling the atmospheric distribution of mineral aerosol: comparison with ground measurements and satellite observations for yearly and synoptic timescales over the North Atlantic, J. Geophys. Res.Atmos., 105, 1997-2012, doi:10.1029/1999jd901084, 2000.

Guieu, C., Bonnet, S., Wagener, T., and Loye-Pilot, M. D.: Biomass burning as a source of dissolved iron to the open ocean?, Geophys. Res. Lett., 32, L19608, doi:10.1029/2005g1022962, 2005.

Hand, J. L., Mahowald, N. M., Chen, Y., Siefert, R. L., Luo, C., Subramaniam, A., and Fung, I.: Estimates of atmospheric-processed soluble iron from observations and a global mineral aerosol model: biogeochemical implications, J. Geophys. Res.-Atmos., 109, D17205, doi:10.1029/2004jd004574, 2004.

Hauglustaine, D. A., Hourdin, F., Jourdain, L., Filiberti, M. A., Walters, S., Lamarque, J. F., and Holland, E. A.: Interactive chemistry in the Laboratoire de Meteorologie Dynamique general circulation model: description and background tropospheric chemistry evaluation, J. Geophys. Res.-Atmos., 109, D04314, doi:10.1029/2003jd003957, 2004.

Hildemann, L. M., Cass, G. R., and Markowski, G. R.: A dilution stack sampler for collection of organic aerosol emissions-design, characterization and field-tests, Aerosol Sci. Tech., 10, 193-204, doi:10.1080/02786828908959234, 1989.

Holscher, D., Moller, R. F., Denich, M., and Folster, H.: Nutrient input-output budget of shifting agriculture in Eastern Amazonia, Nutr. Cycl. Agroecosys., 47, 49-57, 1997.

Hourdin, F. and Issartel, J. P.: Sub-surface nuclear tests monitoring through the CTBT xenon network, Geophys. Res. Lett., 27, 2245-2248, doi:10.1029/1999g1010909, 2000.

Hourdin, F., Musat, I., Bony, S., Braconnot, P., Codron, F., Dufresne, J. L., Fairhead, L., Filiberti, M. A., Friedlingstein, P., Grandpeix, J. Y., Krinner, G., Levan, P., Li, Z. X., and Lott, F.: The LMDZ4 general circulation model: climate performance and sensitivity to parametrized physics with emphasis on tropical convection, Clim. Dynam., 27, 787-813, doi:10.1007/s00382006-0158-0, 2006.

Huang, S. L., Rahn, K. A., Arimoto, R., Graustein, W. C., and Turekian, K. K.: Semi-annual cycles of pollution at Bermuda, J. Geophys. Res.-Atmos., 104, 30309-30317, doi:10.1029/1999jd900801, 1999.

Huneeus, N., Schulz, M., Balkanski, Y., Griesfeller, J., Prospero, J., Kinne, S., Bauer, S., Boucher, O., Chin, M., Dentener, F.,
Diehl, T., Easter, R., Fillmore, D., Ghan, S., Ginoux, P., Grini, A., Horowitz, L., Koch, D., Krol, M. C., Landing, W., Liu, X., Mahowald, N., Miller, R., Morcrette, J.-J., Myhre, G., Penner, J., Perlwitz, J., Stier, P., Takemura, T., and Zender, C. S.: Global dust model intercomparison in AeroCom phase I, Atmos. Chem. Phys., 11, 7781-7816, doi:10.5194/acp-11-7781-2011, 2011.

Ingerslev, M., Skov, S., Sevel, L., and Pedersen, L. B.: Element budgets of forest biomass combustion and ash fertilisation - a Danish case-study, Biomass Bioenerg., 35, 2697-2704, doi:10.1016/j.biombioe.2011.03.018, 2011.

International Energy Agency: Energy Statistics of Non-OECD Countries 1970-2006, OECD/IEA, Paris, 2008.

Ito, A.: Global modeling study of potentially bioavailable iron input from shipboard aerosol sources to the ocean, Global Biogeochem. Cy., 27, 1-10, doi:10.1029/2012gb004378, 2013.

Ito, A.: Atmospheric processing of combustion aerosols as a source of bioavailable iron, Environ. Sci. Technol. Lett., 2, 70-75, doi:10.1021/acs.estlett.5b00007, 2015.

Ito, A. and Feng, Y.: Role of dust alkalinity in acid mobilization of iron, Atmos. Chem. Phys., 10, 9237-9250, doi:10.5194/acp-109237-2010, 2010.

Ito, $\mathrm{A}$. and $\mathrm{Xu}, \mathrm{L}$.: Response of acid mobilization of iron-containing mineral dust to improvement of air quality projected in the future, Atmos. Chem. Phys., 14, 3441-3459, doi:10.5194/acp-14-34412014, 2014.

Johnson, K. S., Gordon, R. M., and Coale, K. H.: What controls dissolved iron concentrations in the world ocean?, Mar. Chem., 57, 137-161, doi:10.1016/S0304-4203(97)00043-1, 1997.

Johnson, M., Edwards, R., Frenk, C. A., and Masera, O. In-field greenhouse gas emissions from cookstoves in rural Mexican households, Atmos. Environ., 42, 1206-1222, doi:10.1016/j.atmosenv.2007.10.034, 2008.

Journet, E., Desboeufs, K. V., Caquineau, S., and Colin, J. L.: Mineralogy as a critical factor of dust iron solubility, Geophys. Res. Lett., 35, L07805, doi:10.1029/2007gl031589, 2008.

Journet, E., Balkanski, Y., and Harrison, S. P.: A new data set of soil mineralogy for dust-cycle modeling, Atmos. Chem. Phys., 14, 3801-3816, doi:10.5194/acp-14-3801-2014, 2014.

Kim, Y., Kim, N. Y., Park, S. Y., Lee, D. K., and Lee, J. H.: Classification and individualization of used engine oils using elemental composition and discriminant analysis, Forensic Sci. Int., 230, 58-67, doi:10.1016/j.forsciint.2013.01.013, 2013.

Kittelson, D. B.: Engines and nanoparticles: a review, J. Aerosol Sci., 29, 575-588, doi:10.1016/S0021-8502(97)10037-4, 1998.

Krinner, G., Viovy, N., de Noblet-Ducoudre, N., Ogee, J., Polcher, J., Friedlingstein, P., Ciais, P., Sitch, S., and Prentice, I. C.: A dynamic global vegetation model for studies of the coupled atmosphere-biosphere system, Global Biogeochem. Cy., 19, GB1015, doi:10.1029/2003gb002199, 2005.

Krishnamurthy, A., Moore, J. K., Mahowald, N., Luo, C., Doney, S. C., Lindsay, K., and Zender, C. S.: Impacts of increasing anthropogenic soluble iron and nitrogen deposition on ocean biogeochemistry, Global Biogeochem. Cy., 23, GB3016, doi:10.1029/2008GB003440, 2009.

Laclau, J. P., Sama-Poumba, W., Nzila, J. D., Bouillet, J. P., and Ranger, J.: Biomass and nutrient dynamics in a littoral savanna subjected to annual fires in Congo, Acta Oecol., 23, 41-50, doi:10.1016/S1146-609x(02)01132-3, 2002. 
Lamarque, J.-F., Bond, T. C., Eyring, V., Granier, C., Heil, A., Klimont, Z., Lee, D., Liousse, C., Mieville, A., Owen, B., Schultz, M. G., Shindell, D., Smith, S. J., Stehfest, E., Van Aardenne, J., Cooper, O. R., Kainuma, M., Mahowald, N., McConnell, J. R., Naik, V., Riahi, K., and van Vuuren, D. P.: Historical (1850-2000) gridded anthropogenic and biomass burning emissions of reactive gases and aerosols: methodology and application, Atmos. Chem. Phys., 10, 7017-7039, doi:10.5194/acp10-7017-2010, 2010.

Latva-Somppi, J., Kauppinen, E. I., Valmari, T., Ahonen, P., Gurav, A. S., Kodas, T. T., and Johanson, B.: The ash formation during co-combustion of wood and sludge in industrial fluidized bed boilers, Fuel Process. Technol., 54, 79-94, doi:10.1016/S03783820(97)00061-1, 1998.

Lee, S., Baumann, K., Schauer, J. J., Sheesley, R. J., Naeher, L. P., Meinardi, S., Blake, D. R., Edgerton, E. S., Russell, A. G., and Clements, M.: Gaseous and particulate emissions from prescribed burning in Georgia, Environ. Sci. Technol., 39, 90499056, doi:10.1021/Es0515831, 2005.

Li, X. G., Wang, S. X., Duan, L., Hao, J., Li, C., Chen, Y. S., and Yang, L.: Particulate and trace gas emissions from open burning of wheat straw and corn stover in China, Environ. Sci. Technol., 41, 6052-6058, doi:10.1021/Es0705137, 2007.

Lin, Y. C., Chen, J. P., Ho, T. Y., and Tsai, I. C.: Atmospheric iron deposition in the northwestern Pacific Ocean and its adjacent marginal seas: the importance of coal burning, Global Biogeochem. Cy., 29, 1-22, doi:10.1002/2013GB004795, 2015.

Linak, W. P. and Miller, C. A.: Comparison of particle size distributions and elemental partitioning from the combustion of pulverized coal and residual fuel oil, JAPCA J. Air Waste Ma., 50, 1532-1544, 2000.

Luo, C., Mahowald, N. M., and del Corral, J.: Sensitivity study of meteorological parameters on mineral aerosol mobilization, transport, and distribution, J. Geophys. Res.-Atmos., 108, 4447, doi:10.1029/2003jd003483, 2003.

Luo, C., Mahowald, N. M., Meskhidze, N., Chen, Y., Siefert, R. L., Baker, A. R., and Johansen, A. M.: Estimation of iron solubility from observations and a global aerosol model, J. Geophys. Res.Atmos., 110, 4447, doi:10.1029/2005jd006059, 2005.

Luo, C., Mahowald, N., Bond, T., Chuang, P. Y., Artaxo, P., Siefert, R., Chen, Y., and Schauer, J.: Combustion iron distribution and deposition, Global Biogeochem. Cy., 22, D23307, doi:10.1029/2007gb002964, 2008.

Mackensen, J., Holscher, D., Klinge, R., and Folster, H.: Nutrient transfer to the atmosphere by burning of debris in eastern Amazonia, Forest Ecol. Manag., 86, 121-128, doi:10.1016/S03781127(96)03790-5, 1996.

Mahowald, N. M., Baker, A. R., Bergametti, G., Brooks, N., Duce, R. A., Jickells, T. D., Kubilay, N., Prospero, J. M., and Tegen, I.: Atmospheric global dust cycle and iron inputs to the ocean, Global Biogeochem. Cy., 19, GB1012, doi:10.1029/2004gb002402, 2005.

Mahowald, N. M., Engelstaedter, S., Luo, C., Sealy, A., Artaxo, P., Benitez-Nelson, C., Bonnet, S., Chen, Y., Chuang, P. Y., Cohen, D. D., Dulac, F., Herut, B., Johansen, A. M., Kubilay, N., Losno, R., Maenhaut, W., Paytan, A., Prospero, J. A., Shank, L. M., and Siefert, R. L.: Atmospheric iron deposition: global distribution, variability, and human perturbations, Annu. Rev. Mar. Sci., 1, 245-278, doi:10.1146/annurev.marine.010908.163727, 2009.
Mahowald, N., Lindsay, K., Rothenberg, D., Doney, S. C., Moore, J. K., Thornton, P., Randerson, J. T., and Jones, C. D.: Desert dust and anthropogenic aerosol interactions in the Community Climate System Model coupled-carbon-climate model, Biogeosciences, 8, 387-414, doi:10.5194/bg-8-387-2011, 2011.

Mamane, Y., Miller, J. L., and Dzubay, T. G.: Characterization of individual fly-ash particles emitted from coal-fired and oil-fired power-plants, Atmos. Environ., 20, 2125-2135, doi:10.1016/0004-6981(86)90306-9, 1986.

Martin, J. H.: Glacial-interglacial $\mathrm{CO}_{2}$ change: the iron hypothesis, Paleoceanography, 5, 1-13, doi:10.1029/Pa005i001p00001, 1990.

Martin, J. H., Gordon, R. M., and Fitzwater, S. E.: The case for iron, Limnol. Oceanogr., 36, 1793-1802, 1991.

Meij, R.: Trace-element behavior in coal-fired power-plants, Fuel Process. Technol., 39, 199-217, doi:10.1016/03783820(94)90180-5, 1994.

Mestdagh, M. M., Vielvoye, L., and Herbillon, A. J.: Iron in Kaolinite: The relationship between kaolinite crystallinity and iron content, Clay Minerals, 15, 1-13, 1980.

Ministry of Environmental Protection of the People's Republic of China: China Environment Yearbook 2008, China Environment Yearbook Inc., Beijing, 2008.

Moore, C. M., Mills, M. M., Arrigo, K. R., Berman-Frank, I., Bopp, L., Boyd, P. W., Galbraith, E. D., Geider, R. J., Guieu, C., Jaccard, S. L., Jickells, T. D., La Roche, J., Lenton, T. M., Mahowald, N. M., Maranon, E., Marinov, I., Moore, J. K., Nakatsuka, T., Oschlies, A., Saito, M. A., Thingstad, T. F., Tsuda, A., and Ulloa, O.: Processes and patterns of oceanic nutrient limitation, Nat. Geosci., 6, 701-710, doi:10.1038/Ngeo1765, 2013.

Moore, J. K., Doney, S. C., and Lindsay, K.: Upper ocean ecosystem dynamics and iron cycling in a global threedimensional model, Global Biogeochem. Cy., 18, GB4025, doi:10.1029/2004gb002220, 2004.

Narodoslawsky, M. and Obernberger, I.: From waste to raw material - the route from biomass to wood ash for cadmium and other heavy metals, J. Hazard. Mater., 50, 157-168, 1996.

Murad, E. and Wagner, U.: The Mossbauer spectrum of illite, Clay Minerals, 29, 1-10, 1994.

Nickovic, S., Vukovic, A., Vujadinovic, M., Djurdjevic, V., and Pejanovic, G.: Technical Note: High-resolution mineralogical database of dust-productive soils for atmospheric dust modeling, Atmos. Chem. Phys., 12, 845-855, doi:10.5194/acp-12-8452012, 2012.

Nickovic, S., Vukovic, A., and Vujadinovic, M.: Atmospheric processing of iron carried by mineral dust, Atmos. Chem. Phys., 13, 9169-9181, doi:10.5194/acp-13-9169-2013, 2013.

Okin, G. S., Baker, A. R., Tegen, I., Mahowald, N. M., Dentener, F. J., Duce, R. A., Galloway, J. N., Hunter, K., Kanakidou, M., Kubilay, N., Prospero, J. M., Sarin, M., Surapipith, V., Uematsu, M., and Zhu, T.: Impacts of atmospheric nutrient deposition on marine productivity: Roles of nitrogen, phosphorus, and iron, Global Biogeochem. Cy., 25, GB2022, doi:10.1029/2010GB003858, 2011.

Olmez, I., Sheffield, A. E., Gordon, G. E., Houck, J. E., Pritchett, L. C., Cooper, J. A., Dzubay, T. G., and Bennett, R. L.: Compositions of particles from selected sources in Philadelphia for receptor modeling applications, JAPCA J. Air Waste Ma., 38, 1392-1402, 1988. 
Pivello, V. R. and Coutinho, L. M.: Transfer of macro-nutrients to the atmosphere during experimental burnings in an open cerrado (Brazilian Savanna), J. Trop. Ecol., 8, 487-497, doi:10.1017/S0266467400006829, 1992.

Querol, X., Fernandez-Turiel, J. L., and Lopez Soler, A.: Traceelements in coal and their behavior during combustion in a large power-station, Fuel, 74, 331-343, doi:10.1016/00162361(95)93464-O, 1995.

Raison, R. J., Khanna, P. K., and Woods, P. V.: Mechanisms of element transfer to the atmosphere during vegetation fires, Can. J. Forest Res., 15, 132-140, doi:10.1139/X85-022, 1985.

Reddy, M. S., Basha, S. B., Joshi, H. V., and Jha, B.: Evaluation of the emission characteristics of trace metals from coal and fuel oil fired power plants and their fate during combustion, J. Hazard. Mater., 123, 242-249, 2005.

Ridgwell, A. J. and Watson, A. J.: Feedback between aeolian dust, climate, and atmospheric $\mathrm{CO}_{2}$ in glacial time, Paleoceanography, 17, GB4028, doi:10.1029/2001pa000729, 2002.

Sager, M.: Trace and nutrient elements in manure, dung and compost samples in Austria, Soil Biol. Biochem., 39, 1383-1390, doi:10.1016/j.soilbio.2006.12.015, 2007.

Schroth, A. W., Crusius, J., Sholkovitz, E. R., and Bostick, B. C.: Iron solubility driven by speciation in dust sources to the ocean, Nat. Geosci., 2, 337-340, doi:10.1038/Ngeo501, 2009.

Schulz, M.: Constraining Model Estimates of the Aerosol Radiative Forcing, Thèse d'Habilitation à Diriger des Recherches, Université Pierre et Marie Curie, Paris VI, 2007.

Schulz, M., Balkanski, Y. J., Guelle, W., and Dulac, F.: Role of aerosol size distribution and source location in a threedimensional simulation of a Saharan dust episode tested against satellite-derived optical thickness, J. Geophys. Res.-Atmos., 103, 10579-10592, doi:10.1029/97jd02779, 1998.

Schulz, M. G., Heil, A., Hoelzemann, J. J., Spessa, A., Thonicke, K., Goldammer, J. G., Held, A. C., Pereira, J. M. C., and van het Bolscher, M.: Global wildland fire emissions from 1960 to 2000, Global Biogeochem. Cy., 22, 1059, doi:10.1029/2007gb003031, 2008.

Schulz, M., Prospero, J. M., Baker, A. R., Dentener, F., Ickes, L., Liss, P. S., Mahowald, N. M., Nickovic, S., Garcia-Pando, C. P., Rodriguez, S., Sarin, M., Tegen, I., and Duce, R. A.: Atmospheric transport and deposition of mineral dust to the ocean: implications for research needs, Environ. Sci. Technol., 46, 1039010404, doi:10.1021/Es300073u, 2012.

Sedwick, P. N., Sholkovitz, E. R., and Church, T. M.: Impact of anthropogenic combustion emissions on the fractional solubility of aerosol iron: evidence from the Sargasso Sea, Geochem. Geophy. Geosy., 8, Q10Q06, doi:10.1029/2007gc001586, 2007.

Shen, G. F., Yang, Y. F., Wang, W., Tao, S., Zhu, C., Min, Y. J., Xue, M. A., Ding, J. N., Wang, B., Wang, R., Shen, H. Z., Li, W., Wang, X. L., and Russell, A. G.: Emission factors of particulate matter and elemental carbon for crop residues and coals burned in typical household stoves in China, Environ. Sci. Technol., 44, 7157-7162, doi:10.1021/Es101313y, 2010.

Shen, G. F., Wei, S. Y., Wei, W., Zhang, Y. Y., Min, Y. J., Wang, B., Wang, R., Li, W., Shen, H. Z., Huang, Y., Yang, Y. F., Wang, W., Wang, X. L., Wang, X. J., and Tao, S.: Emission factors, size distributions, and emission inventories of carbonaceous particulate matter from residential wood combustion in rural China,
Environ. Sci. Technol., 46, 4207-4214, doi:10.1021/Es203957u, 2012.

Sholkovitz, E. R., Sedwick, P. N., and Church, T. M.: Influence of anthropogenic combustion emissions on the deposition of soluble aerosol iron to the ocean: empirical estimates for island sites in the North Atlantic, Geochim. Cosmochim. Ac., 73, 3981-4003, doi:10.1016/j.gca.2009.04.029, 2009.

Sholkovitz, E. R., Sedwick, P. N., Church, T. M., Baker, A. R., and Powell, C. F.: Fractional solubility of aerosol iron: synthesis of a global-scale data set, Geochim. Cosmochim. Ac., 89, 173-189, doi:10.1016/j.gca.2012.04.022, 2012.

Slinn, S. A. and Slinn, W. G. N.: Predictions for particle deposition on natural waters, Atmos. Environ., 14, 1013-1016, doi:10.1016/0004-6981(80)90032-3, 1980.

Smith, R. D., Campbell, J. A., and Nielson, K. K.: Characterization and formation of submicron particles in coal-fired plants, Atmos. Environ., 13, 607-617, doi:10.1016/0004-6981(79)901896, 1979.

Sun, Y. L., Zhuang, G. S., Ying, W., Han, L. H., Guo, J. H., Mo, D., Zhang, W. J., Wang, Z. F., and Hao, Z. P.: The airborne particulate pollution in Beijing - concentration, composition, distribution and sources, Atmos. Environ., 38, 5991-6004, doi:10.1016/j.atmosenv.2004.07.009, 2004.

Tagliabue, A., Bopp, L., and Aumont, O.: Evaluating the importance of atmospheric and sedimentary iron sources to Southern Ocean biogeochemistry, Geophys. Res. Lett., 36, Q10Q06, doi:10.1029/2009gl038914, 2009.

Tang, Q., Liu, G. J., Zhou, C. C., and Sun, R. Y.: Distribution of trace elements in feed coal and combustion residues from two coal-fired power plants at Huainan, Anhui, China, Fuel, 107, 315-322, doi:10.1016/j.fuel.2013.01.009, 2013.

Taylor, S. R. and McLennan, S. M.: The Continental Crust: Its Composition and Evolution, Blackwell, Malden, MA, 312 pp., 1985.

Tegen, I. and Fung, I.: Modeling of mineral dust in the atmospheresources, transport, and optical-thickness, J. Geophys. Res.Atmos., 99, 22897-22914, doi:10.1029/94jd01928, 1994.

Tewalt, S. J., Belkin, H. E., SanFilipo, J. R., Merrill, M. D., Palmer, C. A., Warwick, P. D., Karlsen, A. W., Finkelman, R. B., and Park, A. J.: Chemical analyses in the World coal quality inventory, version 1: U. S. Geological Survey Open-File Report 20101196, available at: http://pubs.usgs.gov/of/2010/1196/ (last access: 10 March 2015), 2010.

Valmari, T., Lind, T. M., Kauppinen, E. I., Sfiris, G., Nilsson, K., and Maenhaut, W.: Field study on ash behavior during circulating fluidized-bed combustion of biomass. 1. Ash formation, Energ. Fuel., 13, 379-389, doi:10.1021/Ef980085d, 1999.

van der Werf, G. R., Randerson, J. T., Giglio, L., Collatz, G. J., Mu, M., Kasibhatla, P. S., Morton, D. C., DeFries, R. S., Jin, Y., and van Leeuwen, T. T.: Global fire emissions and the contribution of deforestation, savanna, forest, agricultural, and peat fires (19972009), Atmos. Chem. Phys., 10, 11707-11735, doi:10.5194/acp10-11707-2010, 2010.

Vassilev, S. V., Baxter, D., Andersen, L. K., and Vassileva, C. G.: An overview of the chemical composition of biomass, Fuel, 89, 913-933, doi:10.1016/j.fuel.2009.10.022, 2010.

Vestreng, V., Myhre, G., Fagerli, H., Reis, S., and Tarrasón, L.: Twenty-five years of continuous sulphur dioxide emission reduction in Europe, Atmos. Chem. Phys., 7, 3663-3681, doi:10.5194/acp-7-3663-2007, 2007. 
Wang, R., Tao, S., Ciais, P., Shen, H. Z., Huang, Y., Chen, H., Shen, G. F., Wang, B., Li, W., Zhang, Y. Y., Lu, Y., Zhu, D., Chen, Y. C., Liu, X. P., Wang, W. T., Wang, X. L., Liu, W. X., Li, B. G., and Piao, S. L.: High-resolution mapping of combustion processes and implications for $\mathrm{CO}_{2}$ emissions, Atmos. Chem. Phys., 13, 5189-5203, doi:10.5194/acp-13-5189-2013, 2013.

Wang, R., Tao, S., Shen, H. Z., Huang, Y., Chen, H., Balkanski, Y., Boucher, O., Ciais, P., Shen, G. F., Li, W., Zhang, Y. Y., Chen, Y. C., Lin, N., Su, S., Li, B. G., Liu, J. F., and Liu, W. X.: Trend in global black carbon emissions from 1960 to 2007, Environ. Sci. Technol., 48, 6780-6787, doi:10.1021/Es5021422, 2014a.

Wang, R., Tao, S., Balkanski, Y., Ciais, P., Boucher, O., Liu, J. F., Piao, S. L., Shen, H. Z., Vuolo, M. R., Valari, M., Chen, H., Chen, Y. C., Cozic, A., Huang, Y., Li, B. G., Li, W., Shen, G. F., Wang, B., and Zhang, Y. Y.: Exposure to ambient black carbon derived from a unique inventory and highresolution model, P. Natl. Acad. Sci. USA, 111, 2459-2463, doi:10.1073/pnas.1318763111, 2014b.

Wang, R., Balkanski, Y., Boucher, O., Ciais, P., Penuelas, J., and Tao, S.: Significant contribution of combustion-related emissions to the atmospheric phosphorus budget, Nat. Geosci., 1, 48-54, 2015.
Wang, Y. F., Huang, K. L., Li, C. T., Mi, H. H., Luo, J. H., and Tsai, P. J.: Emissions of fuel metals content from a diesel vehicle engine, Atmos. Environ., 37, 4637-4643, doi:10.1016/j.atmosenv.2003.07.007, 2003.

Yen, C.: High volume fly ash concrete manufacturing technique and application study, Technical Report for the Taiwan Power Company, 275 pp., Taipei, Taiwan, 2011.

Yi, H. H., Hao, J. M., Duan, L., Tang, X. L., Ning, P., and Li, X. H.: Fine particle and trace element emissions from an anthracite coal-fired power plant equipped with a bag-house in China, Fuel, 87, 2050-2057, doi:10.1016/j.fuel.2007.10.009, 2008.

Zhang, H. F., Ye, X. N., Cheng, T. T., Chen, J. M., Yang, X., Wang, L., and Zhang, R. Y.: A laboratory study of agricultural crop residue combustion in China: emission factors and emission inventory, Atmos. Environ., 42, 8432-8441, doi:10.1016/j.atmosenv.2008.08.015, 2008.

Zhao, Y., Wang, S., Duan, L., Lei, Y., Cao, P., and Hao, J.: Primary air pollutant emissions of coal-fired power plants in China: Current status and future prediction, Atmos. Environ., 42, 84428452, 2008. 